\title{
Precision Animal Feed Formulation: An Evolutionary Multi-Objective Approach
}

\section{Daniel Dooyum Uyeh ${ }^{1}$, Trinadh Pamulapati ${ }^{2}$, Rammohan Mallipeddi ${ }^{2}$, Tusan Park ${ }^{1}$, Senorpe Asem-} Hiablie $^{3}$, Seungmin $\mathbf{W o o}^{1}$, Junhee Kim, Yeongsu Kim ${ }^{1}$, Yushin $\mathbf{H a}^{{ }^{* *}}$

${ }^{1}$ Department of Bio-industrial Machinery Engineering, Kyungpook National University, Daegu 41566, Republic of Korea

${ }^{2}$ School of Electronics Engineering, Kyungpook National University, Daegu 41566, Republic of Korea ${ }^{3}$ Department of Agricultural and Biological Engineering, The Pennsylvania State University, University Park,

$$
\text { PA, 16802, USA }
$$

\section{*Correspondence: Yushin Ha (yushin72@knu.ac.kr)}

\section{Abstract:}

Most livestock producers aim for optimal ways of feeding their animals. Conventional algorithms approach optimum feed formulation by minimizing feed costs while satisfying constraints related to nutritional requirements of the animal. The optimization process needs to be performed every time a nutritional requirement is changed due to the nonlinear relationship between the relaxation of the different nutritional requirements and the feed cost. Consequently, decision-making becomes a time-consuming trial and error process. In addition, the nonlinear relationship changes depending on the type of materials used, their nutritional compositions and costs as well as the animal's nutritional requirements. Therefore, in this work, we formulated a multi-objective feed formulation problem comprising of two objects - a) minimizing feed cost and b) minimizing deviation from the specified requirements. The problem is solved using a population-based evolutionary multi-objective optimization algorithm (NSGA-II) that results in an optimal set of comprised solutions in a single run. The availability of the entire set of comprised solutions facilitates the understanding of the relationship between different nutritional requirements and cost, thus leading to a more efficient decision-making process. We demonstrated the applicability of the proposed method by performing experimental simulations on several cases of dairy and beef cattle feed formulation.

Keywords: Animal feed formulation; Decision-making process; Evolutionary algorithm; Multi-objective optimization; Pareto front 


\begin{tabular}{|c|c|}
\hline Term & Description \\
\hline Met & Methionine \\
\hline Lys & Lysine \\
\hline Arg & Arginine \\
\hline Thr & Threonine \\
\hline Leu & Leucine \\
\hline Ile & Isoleucine \\
\hline Val & Valine \\
\hline His & Histidine \\
\hline Phe & Phenylalanine \\
\hline $\operatorname{Trp}$ & Tryptophan \\
\hline ME & Metabolizable Energy \\
\hline MP & Metabolizable Protein \\
\hline $\mathrm{Ca}$ & Calcium \\
\hline $\mathrm{P}$ & Phosphorous \\
\hline DMI & Dry Matter Intake \\
\hline $\mathrm{MC}$ & Moisture Content \\
\hline TDN & Total Digestible Nutrients \\
\hline $\mathrm{CP}$ & Crude Protein \\
\hline Conc. & Concentrates \\
\hline Rhage & Roughages \\
\hline MOP & Multi-objective optimization \\
\hline LP & Linear Programming \\
\hline KRW & Republic of Korea currency ( $\$ 1=$ about 1130 KRW on February 1, 2019) \\
\hline NSGA-II & Non-dominated sorting based genetic algorithm-II \\
\hline MOEA & Multi-objective evolutionary algorithms \\
\hline EA & Evolutionary Algorithm \\
\hline Nutrient $_{\text {dev }}$ & Deviation from specified nutrient requirement \\
\hline
\end{tabular}


In animal production, the main objective of feed formulation is to provide a balanced nutrition to support physiological functions such as growth, maintenance, reproduction, and lactation as well as energy source for physical and metabolic activities [1]. Research on farm animals have demonstrated that growth rate and milk production depend on the availability of nutrients including amino acids, fatty acids, minerals, glucose, or other substrates [2-4]. In addition, the nutritional requirements of the animal changes depending on different life stages of the animal as well the animals' roles, for example, as seed stock, breeders, or protein providers. Improper balancing of feed nutrients may result in poor nutrition and related diseases and performance problems. In the Republic of Korea, the nutrients emphasized for beef cattle are DMI, MC, TDN, CP, Ca, and P while for dairy cattle, Met, Lys, Arg, Thr, Leu, Ile, Val, His, Phe, Trp, ME, Ca, and P makes up the nutritional requirements [5]. For profitability, feed formulation involves the process of finding the appropriate quantities of different material combinations that meet the nutritional requirements of the animal at minimal cost.

Least-cost feed formulation has been approached as a standard optimization problem where the application of mathematical programming such as LP [6-14], multistage multiple-choice programming algorithm [15], mixed integer programming [16], integer programming [17], mixed integer linear programming [18] has been the norm. The main weaknesses of these approaches is the use of fixed rigid limits that allow the optimization of only one objective at a time and inability to find feasible solutions in many situations $[19,20]$. In other words, in conventional livestock feed formulation, the minimum nutritional requirements are expressed as rigid constraints that needs to be met. Consequently, during optimization, even a small violation regarding any of the nutritional requirements renders solutions to be infeasible and are discarded. Therefore, imposing minimum nutritional requirements may result in feed formulations that are not always cost-effective compared to solutions that are slightly infeasible but still acceptable for the breeder. A slight relaxation of one or more nutritional requirements that may not be essential for a particular growth stage $[21,22]$ may result in a huge reduction of the feed cost while not adversely affecting the performance of the animal. The knowledge of vital nutrient requirements for each stage and its relationship with costs may therefore, help increase the cost-effectiveness of formulated feeds. Based on this observation, an interactive feed formulation using evolutionary algorithm was proposed in [23] where the relaxation of each nutritional requirement is provided to the algorithm through a tolerance parameter. 
Feed formulation usually involves multiple goals (objectives) in addition to minimizing the cost of the feed while satisfying the nutritional requirements. Some of the objectives considered in previous studies include maximizing land-usage [24], maximize the use of stored feeds [25], and reduction of nitrogen and phosphorus excretion [26]. In [27], the authors considered minimizing protein, methionine, and lysine variation in addition to cost minimization. The process of multi-objective optimization involves defining goals and priorities; and then iteratively finding solutions of linear or nonlinear functions. In other words, each goal is solved sequentially according to its priority, with the previous goal or goals held constant in the model. There can be several tradeoffs among multiple conflicting feed formulation objectives. The process results in a set of trade-off solutions referred to as Pareto-optimal solutions. A solution that would improve any of the objectives without sacrificing at least one of the objectives is not possible. In feed formulation literature, goal programming is considered to be a very effective approach for solving multi-objective decision making problems [28]. However, goal programming [29] usually requires the user to set the penalty values for objectives and the choice of the penalties seriously affects the quality of the optimized trade-off solutions resulting in ineffective decision making. Recently, evolutionary multi-objective optimization [30] has been popular due its effectiveness in handling complex nonlinear conflicting objectives without the need for penalties.

As mentioned previously, relaxing some of the constraints related to the nutritional requirements can reduce the cost of the feed formulation without seriously affecting the growth of the animal. In the interactive feed formulation approach described in [23], each nutritional requirement is assigned a tolerance parameter. The change in the tolerance parameter related to the concerned nutritional requirement results in a solution that may or may not be acceptable to the feeder. In other words, to find the relationship between tolerance parameter of each nutritional requirement and the feed cost involves a time-consuming trial and error process. In addition, the decision-making process becomes complicated due to lack of proper understanding between the different nutritional requirements and the feed cost.

In this study, the deviation of the different feed formulations from the specified requirements is considered as an objective to be minimized, in addition to the minimization of the feed cost. The two objectives - a) minimizing the feed cost and b) minimizing the deviation from the specified requirements (Nutrient ${ }_{\text {dev }}$ ) are conflicting. Simultaneous optimization using NSGA-II; an evolutionary multi-objective optimization algorithm was done. The use of evolutionary multi-objective optimization provides as set of comprise solutions (Pareto set) in a single run 
without the need for penalties and priorities set in advance. The shape of the Pareto front, which represents the Pareto set, is dependent on the number and types of nutritional requirements specified for the animal and the cost of feed materials. Therefore, from the Pareto set, we can easily establish the following relationships that can be helpful to the breeder in making better decisions:

a. relationship between the feed cost and the overall deviation from the specified nutritional requirements, b. relationship between the feed cost and the deviation from the individually specified nutritional requirements, and

c. relationship between the different individual nutritional requirements at different feed costs.

\section{Materials, Problem Formulation and Methods}

\subsection{Data}

The feed materials, their nutritional profiles and costs used for the dairy and beef feed ration formulations simulated were obtained from Rural Development Administration of the Republic of Korea. Values are summarized in Tables A1 to A2 of the Supplementary Information. Data on the nutritional requirements of dairy and beef cattle were also obtained from the Rural Development Administration of the Republic of Korea (Table 2 and 3) and these serve as specified nutritional requirements. The nutritional requirements for dairy cattle in the Republic of Korea are arranged as: Met, Lys, Arg, Thr, Leu, Ile, Val, His, Phe, Trp, ME, Ca, and P.

Table 2. Nutritional requirements for different stages of breeding dairy cattle in Republic of Korea

\begin{tabular}{|c|c|c|c|}
\hline & Case 1 & Case 2 & Case 3 \\
\hline Nutrients & $\begin{array}{c}\leq 20 \text { Months } \\
(\leq 500 \mathrm{~kg})\end{array}$ & $\begin{array}{l}20 \text { - } 40 \text { Months } \\
(500-650 \mathrm{~kg})\end{array}$ & $\begin{array}{l}\text { 40-46 Months } \\
\quad(\geq 650 \mathrm{~kg})\end{array}$ \\
\hline ME (kcal) & 25.700 & 65.200 & 30.100 \\
\hline $\mathrm{Ca}(\mathrm{kg})$ & 0.031 & 0.103 & 0.033 \\
\hline $\mathbf{P}(\mathbf{k g})$ & 0.021 & 0.052 & 0.025 \\
\hline Met (kg) & 0.020 & 0.051 & 0.025 \\
\hline Lys (kg) & 0.062 & 0.159 & 0.077 \\
\hline MP (kg) & 0.999 & 2.640 & 1.210 \\
\hline
\end{tabular}

The nutritional requirements of beef cattle in the Republic of Korea are arranged as: DMI, MC, TDN, CP, Ca, and P. The requirements for different cases (categorized by age and weight) considered are summarized in 

normal Rhage requirement.

Table 3. Nutritional requirements for different stages of breeding beef cattle in Republic of Korea

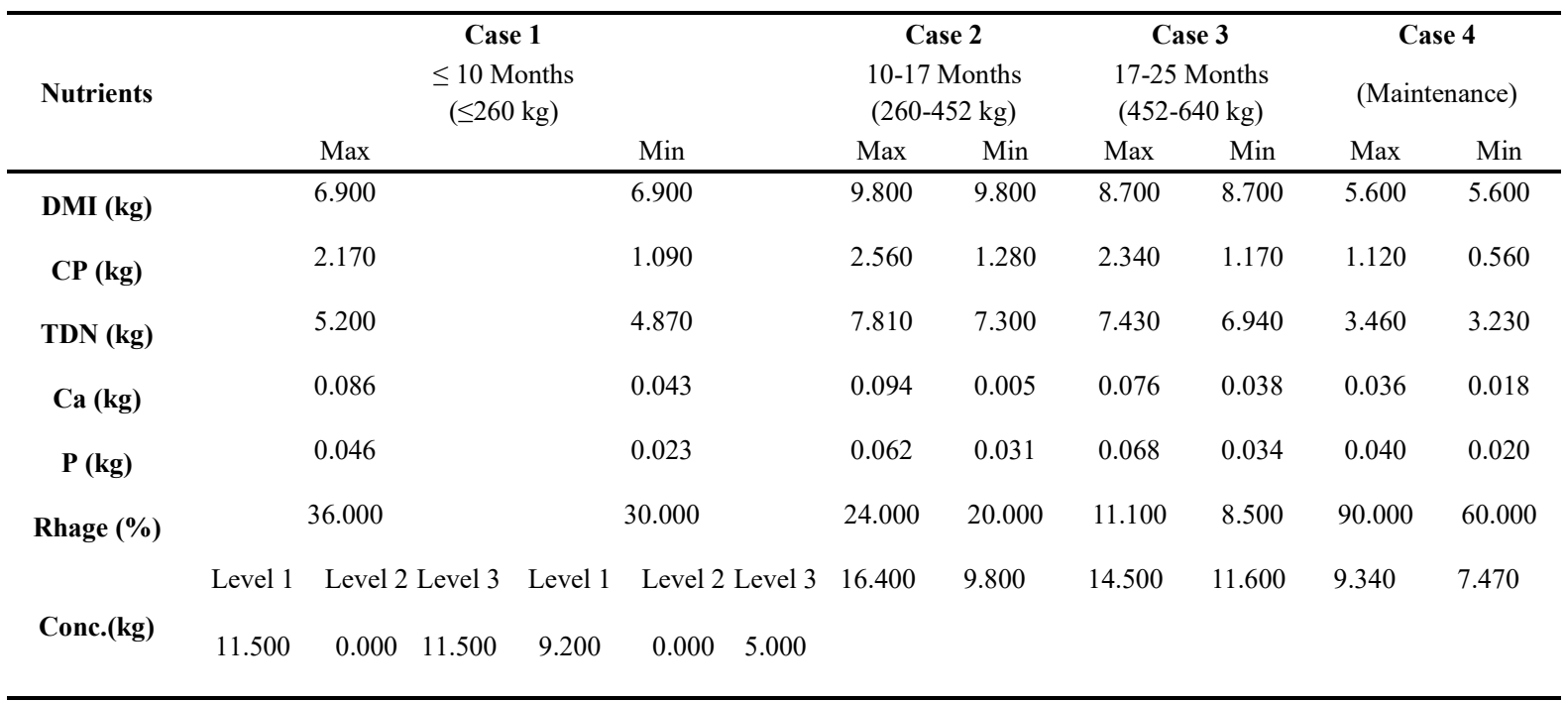

\subsection{Problem formulation}

In feed formulation, enforcing rigid nutritional requirements usually leads to drastic increases in feed costs. On the other hand, relaxing some of the constraints reduces the feed cost while not affecting the physiological

117 characteristics of the animal. The nutritional requirements that can be relaxed depends on the type and developmental stage of the animal as well as its condition. In addition, the nutritional requirements during feed formulation vary in different regions. The DMI $(\mathrm{kg})$ is the amount of dry matter consumed daily while CP (\%) measures the nitrogen content, including both true protein and non-protein nitrogen. The summation of the digestible fiber, protein, lipid, and carbohydrate components of a feed ration is referred to as TDN and is directly related to digestible energy. Minerals are vital components of feed with at least 17 minerals required. However, the two mostly included in computer models are $\mathrm{Ca}$ and $\mathrm{P}$. Calcium is the most abundant mineral in the body with approximately $98 \%$ as a structural component of bones and teeth. The remaining $2 \%$ is distributed in extracellular fluids and soft tissues and is involved in such vital functions as blood clotting, membrane permeability, muscle contraction, transmission of nerve impulses, cardiac regulation, secretion of certain hormones, and activation and stabilization of various enzymes [2]. 

dairy and beef cattle.

\section{Single objective formulation for Dairy cattle}

Minimize $\sum_{i=1}^{n} w_{i} \operatorname{cost}_{i} \geq 0$

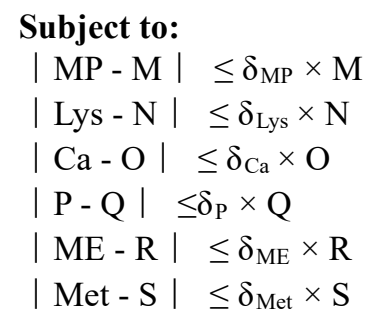

\section{Single objective formulation for Beef cattle}

Minimize $\sum_{i=1}^{n} w_{i} \operatorname{cost}_{i} \geq 0$

\section{Subject to:}

$$
\begin{aligned}
& |\mathrm{DMI}-\mathrm{A}| \leq \delta_{\mathrm{DMI}} \times \mathrm{A} \\
& |\mathrm{CP}-\mathrm{B}| \leq \delta_{\mathrm{CP}} \times \mathrm{B} \\
& |\mathrm{TDN}-\mathrm{C}| \leq \delta_{\mathrm{TDN}} \times \mathrm{C} \\
& |\mathrm{Ca}-\mathrm{D}| \leq \delta_{\mathrm{Ca}} \times \mathrm{D} \\
& |\mathrm{P}-\mathrm{E}| \leq \delta_{\mathrm{P}} \times \mathrm{E} \\
& |\mathrm{Rhage}-\mathrm{F}| \leq \delta_{\text {Rhage }} \times \mathrm{F} \\
& |\mathrm{MC}-\mathrm{G}| \leq \delta_{\mathrm{MC}} \times \mathrm{G} \\
& \mid \text { Conc. }-\mathrm{H} \mid \leq \delta \mathrm{P}_{\text {Conc. }} \times \mathrm{H}
\end{aligned}
$$

In each problem formulation, the corresponding tolerance parameter $(\delta)$ was used to provide relaxation to the requirements.

134 In these formulations, the breeder can change the tolerance parameter of the requirement to be relaxed and optimize the solution using evolutionary algorithms. The change of the tolerance parameter results in the change of the cost. However, the relationship between the different tolerance parameters and the cost of the feed is not evident and the process of finding the best feed formulation involves a time-consuming trial and error process.

In this work, the constraints related to the different nutritional requirements are combined to form an objective function and is simultaneously optimized with the feed cost. These two objectives conflict with each other and can be referred to as multi-objective formulations. The multi-objective formulations for dairy and beef cattle are shown in equations (3) and (4) below. 
142 As mentioned earlier, the problem was formulated based on inspiration from a previous study [32], where the tolerance parameter had to be changed in order to adjust to the requirements and cost needs of the formulator thus,

144 the simulation must be done every time the tolerance parameter is changed. Consequently, in the new formulation, the constraints were formulated as an objective to eliminate repeated simulations while using Pareto fronts for nondominated solutions to be chosen as optimal if no objective can be improved without compromising at least one objective. Consequently, like in the first objective of minimizing cost using equation 3 , Where $\left(w_{i}\right)$ the weight of the selected material multiplied by the cost $\left(\operatorname{cost}_{i}\right)$ is summed, the constants $\mathrm{M}, \mathrm{N}, \mathrm{O}, \mathrm{Q}, \mathrm{R}$ and $\mathrm{S}$ representing the nutritional requirement of dairy cattle evaluated with the materials during the search process were summed to find the cost at every search space (Pareto front). The viewing of all the constraints along the Pareto front gives the possibility of displaying the various combinations of nutrient contents and corresponding cost.

Instance 1: Dairy cattle

$$
\text { Minimize } \sum_{i=1}^{n} w_{i} \operatorname{cost}_{i}
$$

\section{Objective 2: Deviation from specified nutrient requirements}

$$
\text { Minimize }|\mathrm{MP}-\mathrm{M}|+\mid \text { Lys }-\mathrm{N}|+| \mathrm{Ca}-\mathrm{O}|+| \mathrm{P}-\mathrm{Q}|+| \mathrm{ME}-\mathrm{R}|+| \text { Met }-\mathrm{S} \mid
$$

In dairy cattle, $n$ is the number of ingredients under consideration $w_{\mathrm{i}}$ is the weight in $\mathrm{kg}$ and $\cos t_{\mathrm{i}}$ is the cost $(\mathrm{KRW} / \mathrm{kg}$ ) of the feed materials. Correspondingly, the constants M, N, O, Q, R and S specify the requirements for MP, Lys, Ca, P, ME and Met, respectively; The requirements change with the age and weight of the cattle.

Instance 2: Beef cattle 


\section{Objective 2: Deviation from specified nutrient requirements}

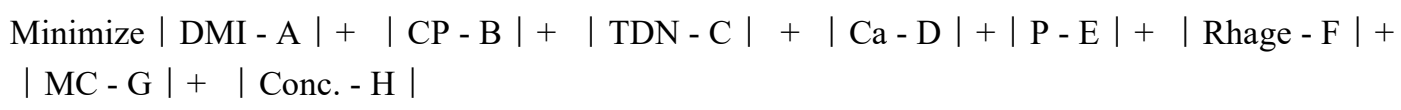

where, $n$ is the number of ingredients under consideration, $w_{\mathrm{i}}$ is the weight in kilograms and $\operatorname{cost}_{\mathrm{i}}$ is the cost $(\mathrm{KRW} / \mathrm{kg})$.

The constants A, B, C, D, E, F, G, and H specify the requirements for DMI, CP, TDN, Ca, P, Rhage, MC and Conc., respectively. The requirements change with the age and weight of the cattle.

Unlike in single objective formulation, the multi-objective approach involves no trial and error process. In addition, the set of comprise solutions over the different feed costs and levels of nutritional requirement satisfaction are obtained. The availability of the whole set of trade-off solutions facilitates better decision making compared to a single objective trial and error approach.

\subsection{Method employed in the current study}

In multi-objective optimization, due to the conflicting nature of the objectives, there exists no single optimal solution, but a set of compromise solutions referred to as Pareto front (in objective space) or Pareto set (in variable space) as shown in Figure 1. As shown, there exists multiple Pareto fronts and the aim of multi-objective algorithms is to find an optimal Pareto front. In other words, optimal Pareto front refers to a set of solutions compared to which there exists no solution that is better in all the objectives. In addition, the solutions in the Pareto front should be well-spread or diverse to enable better decision making.

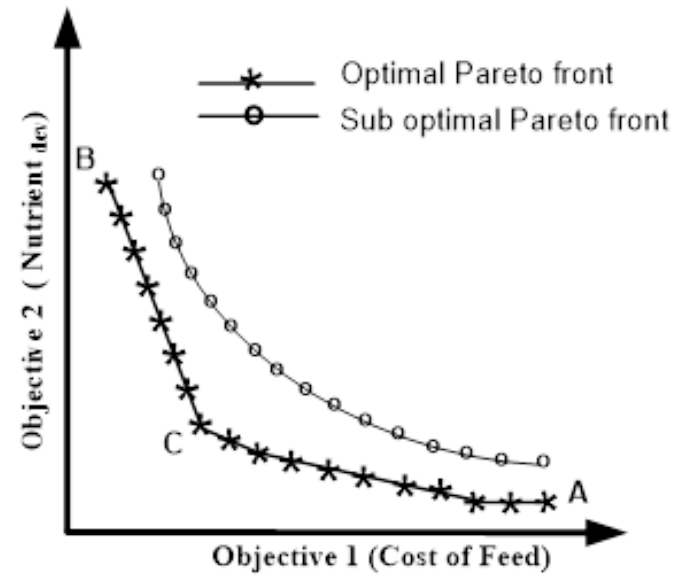

Figure 1. Comparison between MOP and conventional single optimization 
187 a. Single objective optimization specifying weights for each objective. Depending on the set of the weights

188 the algorithm provides a single solution on the Pareto front. Therefore, to estimate the entire Pareto front, multiple runs with different combination of weights is needed. However, it is difficult to find diverse well spread solutions due to the nonlinear relationship between the weights and the Pareto front. Goal programming, that is commonly adopted in feed formulation belongs to this category.

b. Evolutionary multi-objective optimization [28] being a population-based approach can provide the entire Pareto front in a single run.

In terms of feed optimization, the Pareto optimal solutions refers to a set of comprise solutions (Figure 1) where: Point $\mathrm{A}$ is a solution with most nutritional requirement satisfaction but incurs high cost; Point $\mathrm{B}$ is a solution with least cost but deviation from the nutritional requirements is high; and Point $\mathrm{C}$ represents a compromise solution where the cost is significantly reduced with huge deviation in the nutrient requirements. The decision-making process depends on the shape of the Pareto front which in turn mainly depends on the nutritional composition and cost of the individual materials and nutritional requirements. In addition, the relationship between the different nutritional requirements over the entire cost range can be obtained. Therefore, the availability of the entire Pareto front in one run displaying the relationship between individual nutritional requirements facilitates a better decision making.

In this study, we employed the NSGA-II, an evolutionary multi-objective optimization algorithm [33] to optimize the multi-objective problems shown in Equations (3) and (4). To obtain a diverse set of Pareto-optimal solutions, NSGA-II adopts the concepts of Pareto dominance and the crowding distance. More details regarding NSGA-II are provided in the Appendix.

\subsection{Experimental setup and simulations}

The proposed multi-objective feed formulation is simulated using - a) 3 Cases of dairy cattle and b) 4 Cases of beef cattle in the Republic of Korea as shown below and summarized in Tables 2 and 3.

\section{Dairy:}

Case 1: Birth to 20 months and live weights of less than $500 \mathrm{~kg}$

Case 2: Age 20 to 40 months with live weights between 500 and $650 \mathrm{~kg}$

Case 3: Age 40 - 46 months with live weights above $650 \mathrm{~kg}$

Beef:

Case 1: Birth to 10 months with live weights of $260 \mathrm{~kg}$ or less 
217 Case 3: Age 17 to 25 months with live weights between 452 and $640 \mathrm{~kg}$

218 Case 4: Maintenance stage where the farmers attempt to sustain the weight of the animal at a minimal cost.

219 The simulations were performed in MATLAB and an average run time for each simulation of the proposed algorithm was 20 seconds on a $3.7 \mathrm{GHz}$ Intel Core i5 processor, 8 GB RAM and 128 GB solid-state drive with a Windows 10 Operating System. The parameters of the optimization algorithm were set as: Population size: 300

Mutation: Polynomial mutation

Constraint bond: 0-20.

\section{Results and Discussion}

\subsubsection{Dairy: Case 1}

Pareto-optimal front for the two objectives is shown in Figure 2(A) and the quantity of different feed materials selected among solutions on the front, points P1, P2, and P3 are presented in Figure 2(B). Figures 2(C) to 2(H) present the relationship between the feed cost and individual nutritional requirements in the feed. These graphs provide insights into the contribution of the individual nutrient requirements to the total cost. In Figure 2(A), P1 represents a solution where most of the nutritional requirements are met at a cost of approximately $4000 \mathrm{KRW}$. In Figure 2(C) to 2(H), the horizontal dotted lines represent the specified requirement $(\mathrm{OL})$ for the corresponding feed components while OLC represents the cost region over which the corresponding nutritional requirement is satisfied.

242 In Figure 2(A), Point P2 seems to have approximately the same deviation from the requirements as that of P1 but at a significantly less cost of $1300 \mathrm{KRW}$. Also, at P2, five out of the six specified nutritional requirements by the Rural Development Administration of the Republic of Korea are met. However, Ca deviates significantly from 
245 the requirement. In the region between P1 and P2, the increase in the cost is mainly due to the attempt by the

246 algorithm to meet the Ca requirement. However, this results in slight deviations in other nutritional requirements

247 such as Met, P and MP. In Figure 2(A), P3 represents a point where ME, Ca and P requirements are met while the

248 deviations in the requirements of MP, Lys, and Met is observed. The cost variation in the region between P2 and

249 P3 is mainly due to the attempt by the algorithm to satisfy the MP requirement. In order to satisfy the MP, Met

250 and Lys, the Ca deviates from the requirement (Figure 2).

251 From the Figure 2, it is evident that P1 is a point where the specified nutrients were reasonably satisfied. However,

252 moving to the left-hand side from P1 to P2, the overall deviation remains approximately the same with a major

253 deviation in Ca. Therefore, if deviation from the specified Ca can be tolerated, then selection of P2 would result

254 in cost reduction of $223 \%$ compared to P1. In dairy cattle, the requirement of MP depends on different factors

255 such as age and activity of the animal. In [34], it has been reported that the milk yield and milk protein percentage

256 did not improve in Chinese Holstein dairy cows even when their diets contained specified MP. Therefore, in this

257 scenario, if the emphasis is on ME (Figure 2C) then the selection of $\mathrm{P} 3$ would result in cost reduction of $160 \%$

258 compared to P2 with little impact on the quality of the feed with likely small consequences.

259 From Figure 2B and Table A1 in the appendix, it is evident that the algorithm selected a high quantity of autumn 260 forage at the three points (P1, P2 and P3) because of its low cost and parallel nutritional content. Also, the autumn 261 forage contains a high ME which explains the satisfaction of this constraint at these 3 points. At P1 and P2, molasses with a reasonable content in Ca compared to the other nutrients was selected indicating the excess content of $\mathrm{Ca}$ at these points. The excess $\mathrm{Ca}$ is due to the initial selection of cheaper materials usually with high content of $\mathrm{Ca}$ as products with moderate amounts of $\mathrm{Ca}$ and high amounts of other nutrients are usually costlier. 

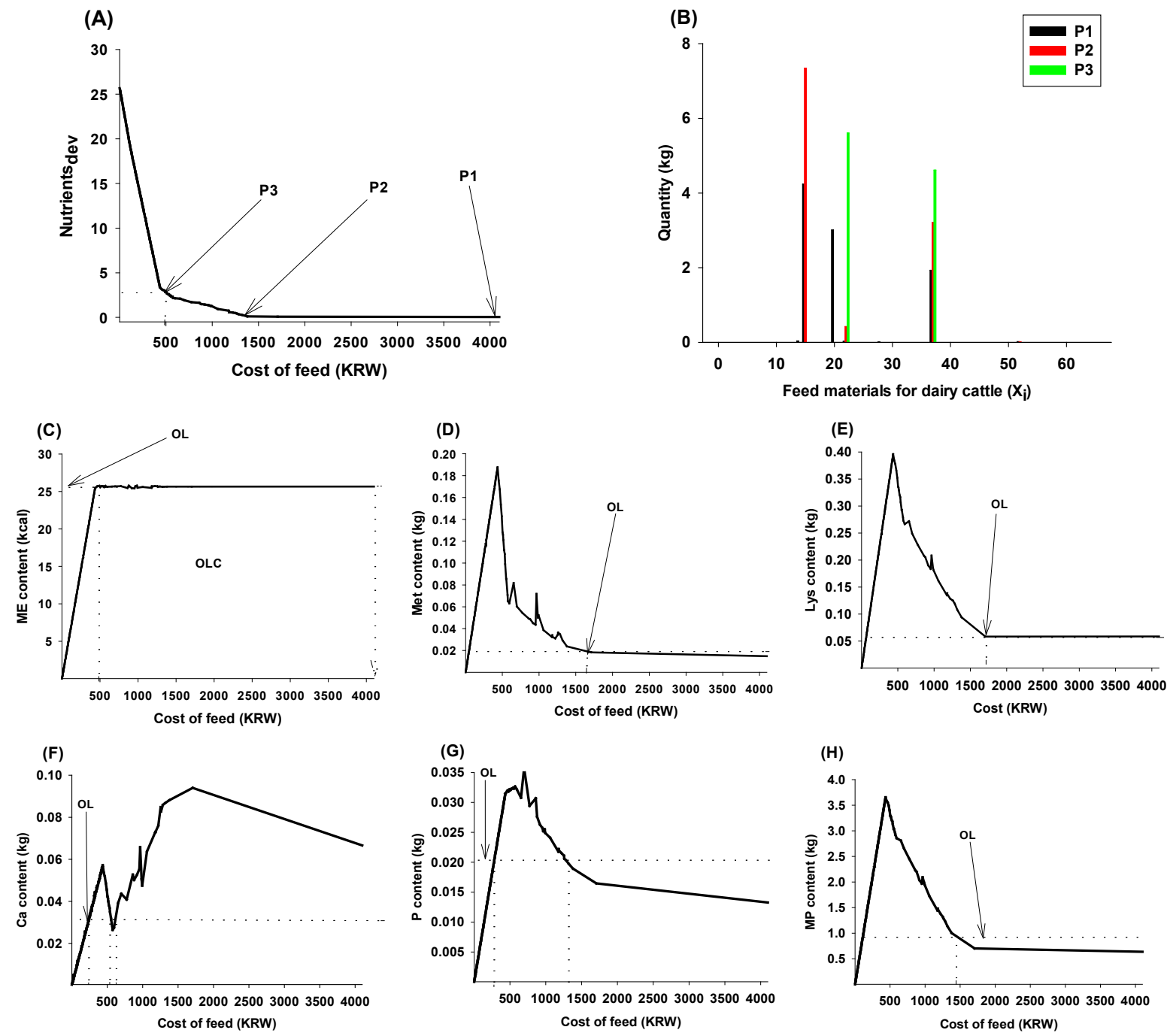

Figure 2. Feed formulation curves for dairy cattle Case 1 (OL: Optimal Line; P1, P2, P3: Points; OLC: Optimal Line Cost; Nutrient dev: Deviation in specified nutrients requirement)

\subsubsection{Dairy: Case 2}

For Case 2, the Pareto-optimal front is shown in Figure 3(A) with P1, P2 and P3. The different feed materials selected at these points are presented in Figure 3(B). Figures 3(C) to 3(H) present the relationship between the feed cost and individual nutritional components present in the feed. As mentioned in Case 1, OL and OLC represent the specified requirement and the cost region which the corresponding nutritional requirement is satisfied, respectively.

From Figure 3(A), it is evident that small deviations from the feed requirements were observed between 3600 
with all the other requirements. In other words, as the cost of the feed increased, the nutritional requirements such as Met, Lys, P and MP in the feeds decreased while Ca increased.

As in Case 1, Case 2 also recorded satisfaction of ME at a lower cost (P3) and showed some stability from P3 to P1. As in Case 1, depending on the user's needs, different solution regions can be selected with varied associated costs. In the selected materials, Figure 3(B), the algorithm also opted for autumn forage in the points (P1 to P3).
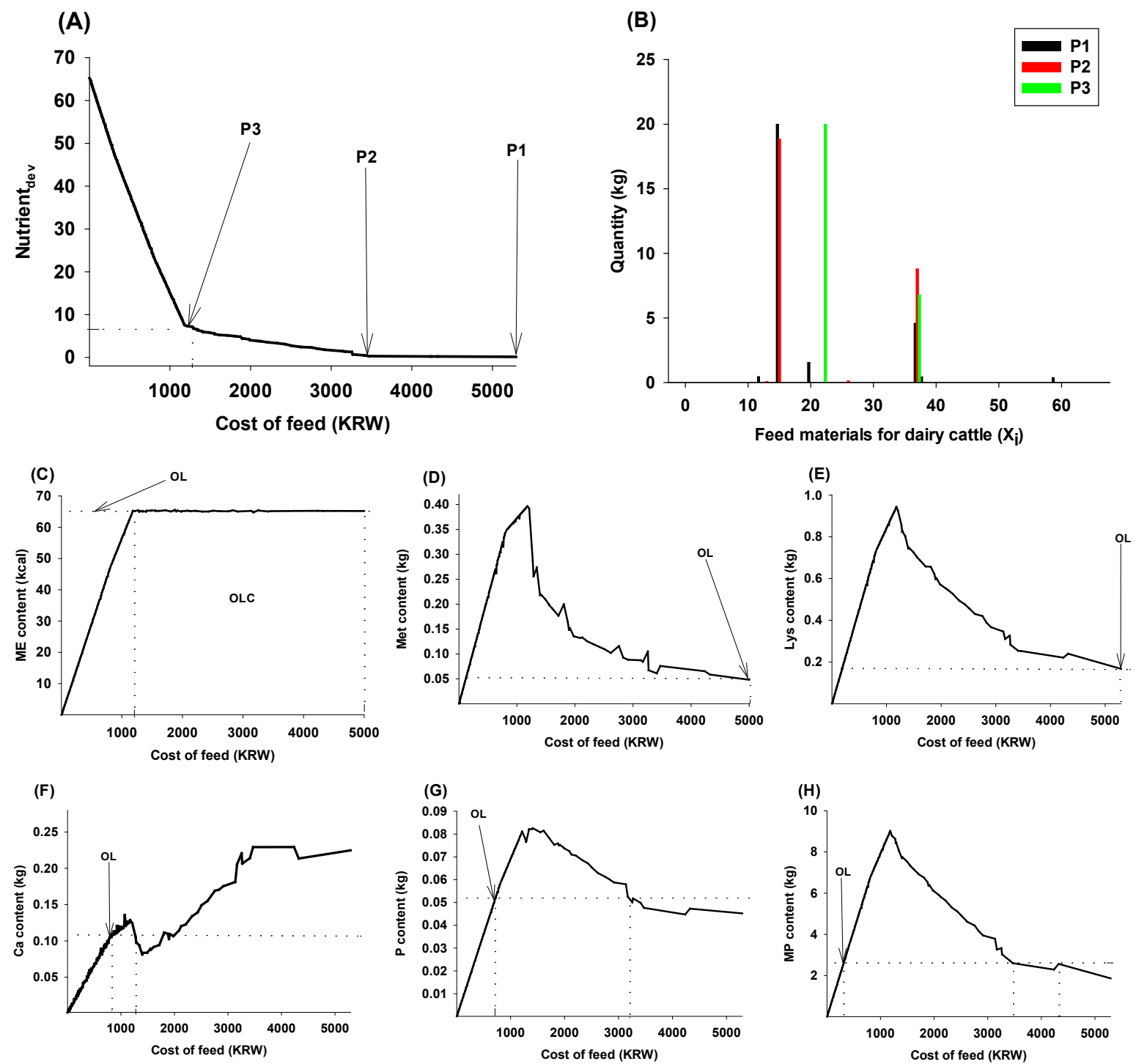

Figure 3. Feed formulation curves for dairy cattle Case 2 (OL: Optimal Line; P1, P2, P3: Points; OLC: Optimal Line Cost; Nutrient ${ }_{\mathrm{dev}}$ : Deviation in specified nutrients requirement)

This further verifies the satisfaction of ME at all the points investigated. High amounts of barley silage were selected at P3 compared to the high levels of molasses selected at P1 and P2. The low cost of barley silage and high nutritional content compared to the relatively expensive molasses with only measurable ME, Ca and P content (Figures 3(C), 3(F) and 3(G)) explains the nutrient excesses recorded at P3 (Figures 3(D), 3(E), 3(G) and 3(H) 
and near specified content recorded at P1 and P2. This shows that the algorithm tries to satisfy the first objective which is cost and then subsequently tries to balance the specified nutrients.

\subsubsection{Dairy: Case 3}

Figure 4 summaries the results for Case 3. At P1, the near specified requirements were observed. However, moving leftward to P2, Met (Figure (4D)), Lys (Figure (4E)) and MP (Figure (4H)) deviated from the specified values while the satisfaction of P (Figure (4G)) was met. However, as we move towards the left to P3, except Ca, all the other nutritional requirement deviate from the specified requirement. However, if the emphasis is only on ME then selecting P3 would result in 220\% reduction in the cost compared to P2. and P2 (Figure (4B)) was the cause of the excesses and satisfaction of the specified requirement respectively.
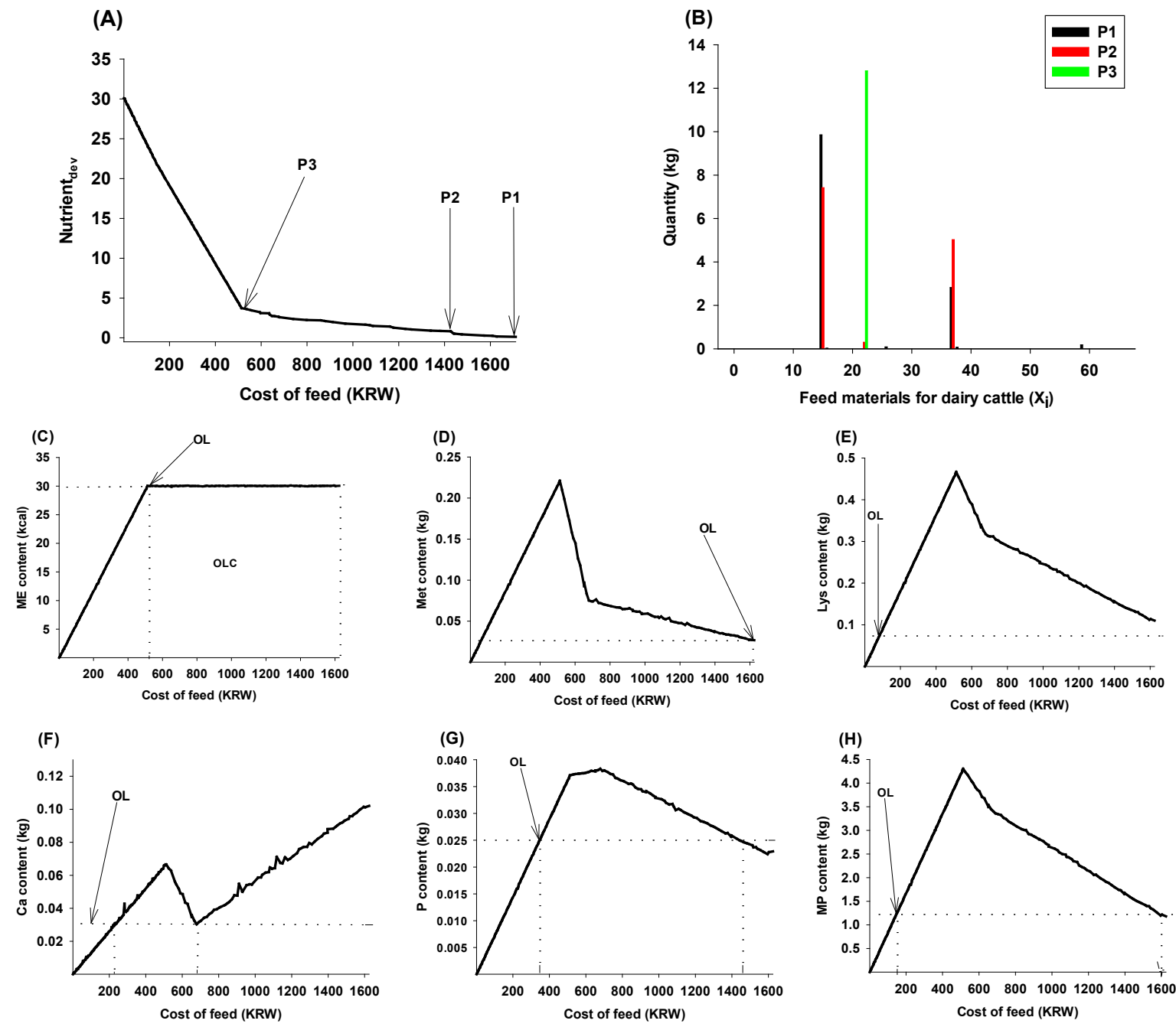

Figure 4. Feed formulation curves for dairy cattle Case 3 (OL: Optimal Line; P1, P2, P3: Points; OLC: Optimal 
In beef cattle, the two main feed types, roughages (Rhage) and concentrates (Conc.), are used in varying combinations in different countries with one often dominating the other at different stages of the animal's growth $[27,35]$. Beef cattle are usually fed predominantly Rhage after weaning until the finishing stage when more Conc. is fed [36, 37]. The primary role of Conc. [36] is to provide concentrated nutrition and energy in the diet of the animal. Globally, a wide variety of cereals and grains and their by-products constitute Conc. fed to animals. As cereals and grains are often the costlier feed types, some substitution with by-products such as distillers grains helps reduce costs. Advantageously, from an economic and physiological perspective, it is possible to increase feed digestibility (a limiting factor for high forage diets) with relatively small quantities of grains and cereals without sacrificing animal growth and performance. Furthermore, other concentrated forms of nutrients that are cost effective such as supplements (Table A2) can be used to make up any nutrient shortages as needed. Therefore, the constraints around the amounts of concentrates fed can be easily relaxed. In the current study, we performed experimental simulations for 3 different levels of Conc. and a fixed Rhage as shown in Table 3. Figure 5 shows the simulated results obtained for 3 Levels of Conc. for the first stage of beef cattle (Case 1) in Republic of Korea. Each column in Figure 5 represents the results corresponding to each of the 3 Levels considered. The specified optimal satisfaction regions are denoted with OR and the optimal region cost is denoted with ORC. Level 1 represents the recommended nutrients and feed types for the beef cattle by the Rural Development Administration of the Republic of Korea. In Level 1, all specified requirements were satisfied at P1 except for Rhage which was not possible at any feed cost. Moving leftwards to P2, specified CP, TDN, P, and DMI (Figure 5, Level 1(C), (D), (F) and (I) were satisfied with Ca (Figure 5, Level 1(E) and Conc. (Figure 5, Level 1(H)) deviating from the specified values while only recommended $\mathrm{Ca}$ (Figure 5, Level 1E) was met at P3 (Figure 5, Level 1(A)). In Figure 5B, the dominant materials selected at P1 and P2 was corn gluten feed while at P3, it was molasses. However, a higher amount of the corn gluten feed was selected at P1 than P2. This could be attributed to the molasses substituting for deficient nutrients at P2. Also, the selection of corn gluten feed with less $\mathrm{Ca}$ content compared to molasses at $\mathrm{P} 3$ led to an excess of $\mathrm{Ca}$ at $\mathrm{P} 3$ (Figure 5, Level 1(A)). If the emphasis is on TDN, $\mathrm{Ca}, \mathrm{P}$, Conc. and DMI (Figures 6, Level 1(D-H) and (I), the selection of P2 where these were satisfied will enable a $125 \%$ cost reduction from P1 where all the specified nutrients with exception of Rhage were met. 
Level 1
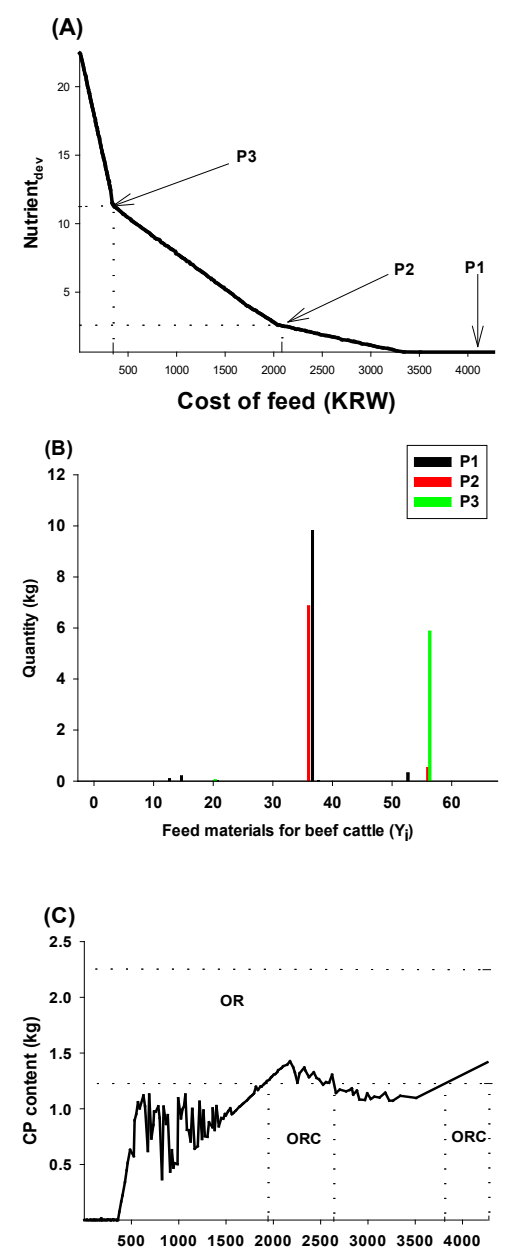

Cost of feed (KRW)
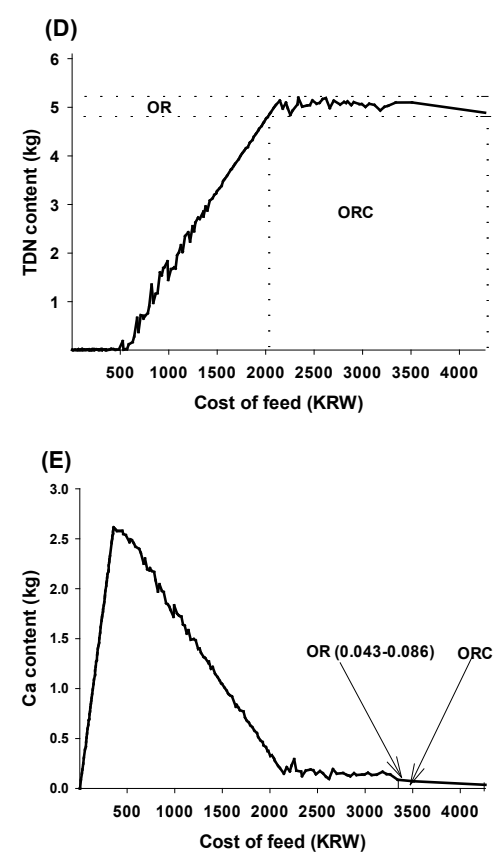

Level 2
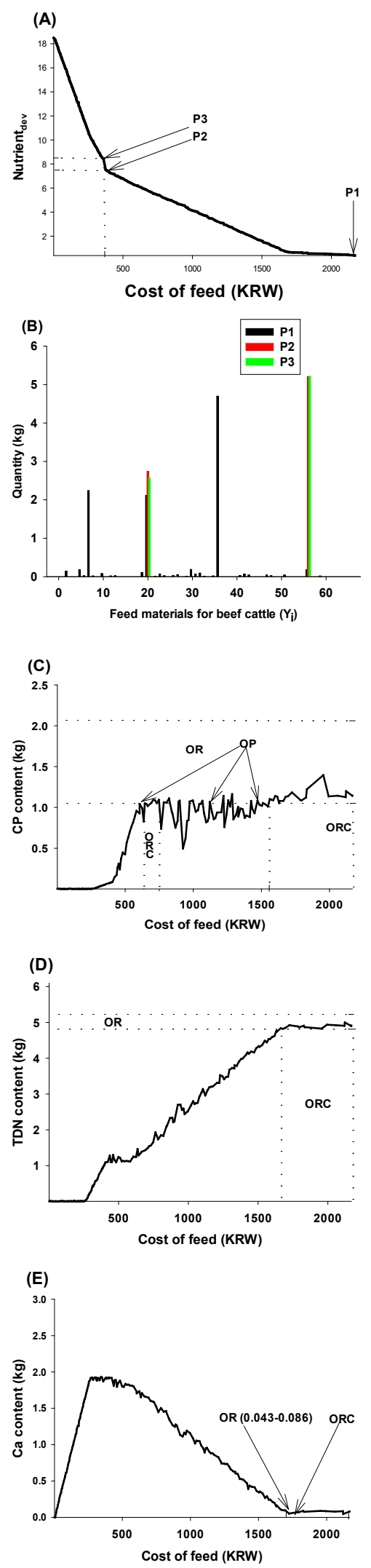

Level 3
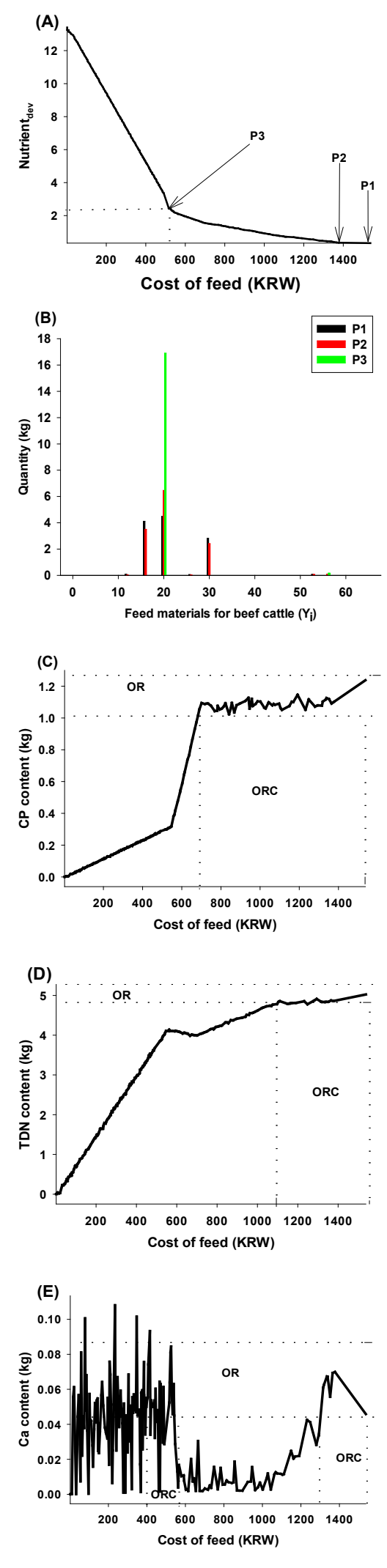

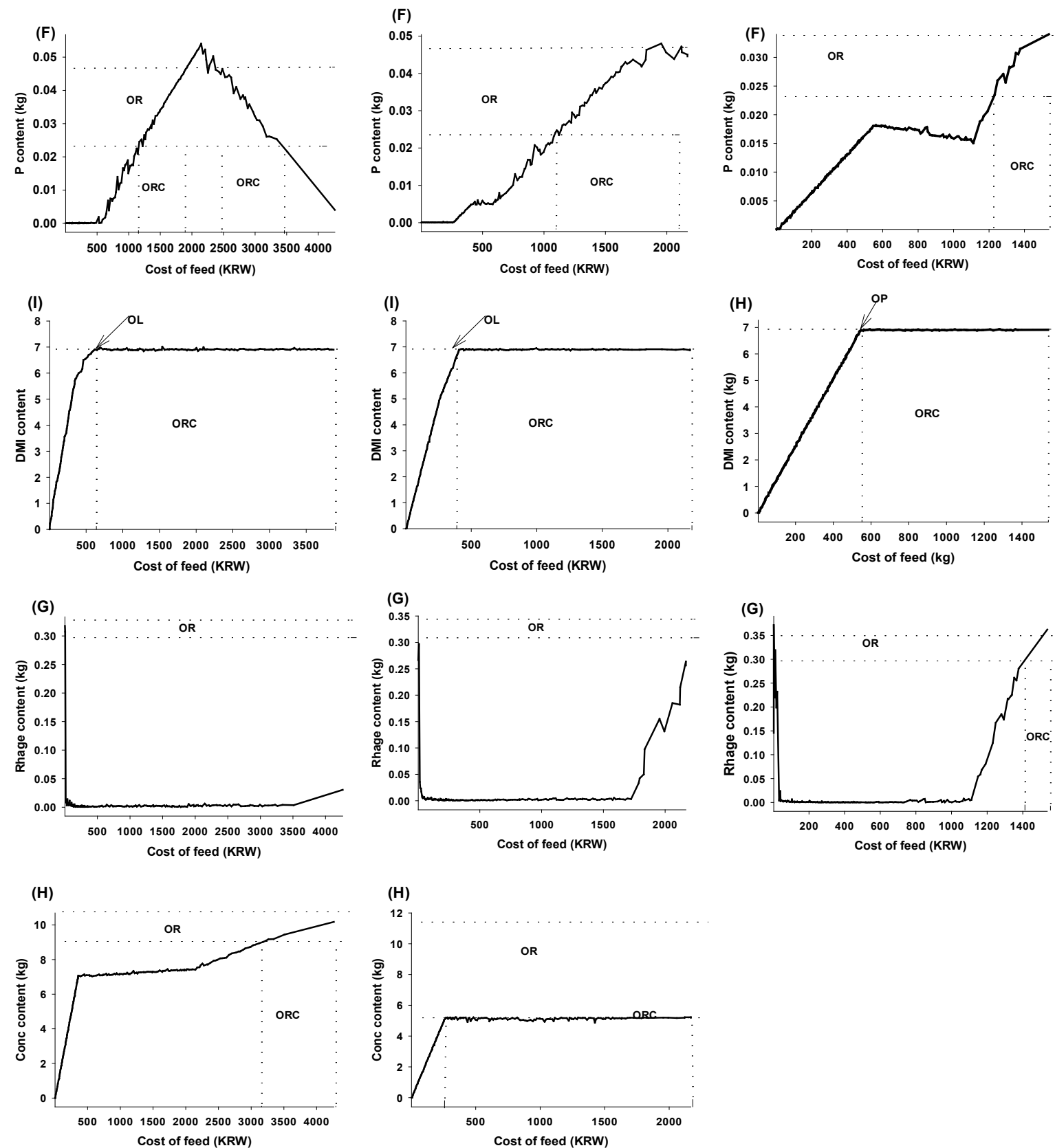

Figure 5. Feed formulation curves for beef cattle Case 1 with each column representing the results corresponding to each of the 3 Levels considered where Levels 1, 2 and 3 are different levels of concentrates respectively. (OR: Optimal Region; P1, P2, P3: Points; ORC: Optimal Region Cost; OP: Optimal Point; Nutrient $\mathrm{d}_{\mathrm{dv}}$ : Deviation in specified nutrients requirement)

In Level 2, we investigated the nutrient deviation curve (Figure 5, 2(A)) with a relaxed Conc. requirement. The results showed conflicts between Rhage and Conc. In this Case, the specified Conc. requirement by the Rural Development Administration of the Republic of Korea was reduced by $50 \%$ while the Rhage was fixed. In P1, a higher selection of brewers' grain was recorded alongside different materials (Alfalfa hay, cornmeal and bakery 
by-products). This explains why the P1 had a better feed solution with the specified nutrient content. Multiple feed solutions with diverse nutrient contents and similar costs were recorded in Level 2 as explained in the previous section. Two solutions, (P2 and P3) were selected from this region and analyzed. For P2 and P3, $2.60 \mathrm{~kg}$ and $2.74 \mathrm{~kg}$ of brewers' grain, respectively were selected while $5.22 \mathrm{~kg}$ and $5.21 \mathrm{~kg}$ of limestone were selected for $\mathrm{P} 2$ and $\mathrm{P} 3$ in that order. However, the higher amounts of brewers' grain at $\mathrm{P} 2$ resulted in better costs and higher nutrients content than the $\mathrm{P} 3$ region. Sudan grass and corn gluten feed were selected at P1 while these were absent in the other two points. The selection of these two components facilitated the satisfaction of the specified quantities for TDN, P and Rhage that were violated in P2 and P3.

In Level 3, a different Pareto front was obtained (Figure 5, Level (3A)). At P1, all specified nutrient amounts were perfectly satisfied (Figures 5, Level $3(\mathrm{C}-\mathrm{H})$. However, moving leftwards from P1 to P2, only the specified quantity for Rhage (Figure 3(G)) was not met at P2. The Rhage content at P2 fell short by $0.02 \mathrm{~kg}$. This shows that a $14 \%$ cost reduction can be recorded if the $0.02 \mathrm{~kg}$ can be tolerated. As in Level 1, only the specified amount for Ca was satisfied at P3. The results in the Level 3 further verifies the conflict between Conc. and Rhage requiring a tradeoff as recorded mostly in feed formulation [27]. In Level 3, various quantities of corn meal were selected at the three points (P1 to P3) because of its low cost and nutrient content compared to other by-products. Also, compared to the other low-cost by-products, it has the most TDN which is vital in cattle feed formulation. Italian ryegrass and bakery by-products were selected at P1 and P2 for balancing the ration. The lesser selection of Italian ryegrass in P2 compared to P1 led to the insufficiency in the specified Rhage requirement in P2.

From Figure 5, it can be observed that nutritional requirements, Conc. and Rhages, conflict each other and as such, as the requirement of Conc. was relaxed (Level 1 to Level 3) finding feed formulations that satisfy the Rhages was possible. In addition, the cost of the feed at which all the requirements were met kept decreasing. That is, in Level 1, it was not possible to find a feed formulation that could satisfy all the requirements even at a cost of over $4000 \mathrm{KRW}$. However, in Level 2 and Level 3, the algorithm was able for find feed formulations that met all the requirements at cost of approximately $2500 \mathrm{KRW}$ and $1450 \mathrm{KRW}$. Comparing the 3 Levels showed that the cost of the feed formulated at Level 3 was 30\% lower than Level 2 and $65 \%$ less than Level 1. Level 2 feed formulation was 50\% lower than Level 1 .

\subsubsection{Beef: Case 2}

P1 and P2 showed a close distance in the Pareto front with the P2 costing 13\% less (Figure 7A). However, the P2 fell short in the specified TDN (Figure 7D) content by $0.3 \mathrm{~kg}$. Even though the P1 solution for Rhage fell 

was better than the amount in P1. In this stage of growth (Case), $0.12 \mathrm{~kg}, 0.33 \mathrm{~kg}$ and $9.61 \mathrm{~kg}$ were selected for P1, P2 and P3 respectively. The high amount of limestone selected in P3 enabled the satisfaction of DMI (Figure 7I) and $\mathrm{Ca}$ (Figure 7E) because of the less content of water and high amount of $\mathrm{Ca}$ (Figure 7E). Similar amount of corn gluten feed was selected for both P1 and P2. The selected rice straw at P1 enabled the better satisfaction of Rhage at this point compared to P2.
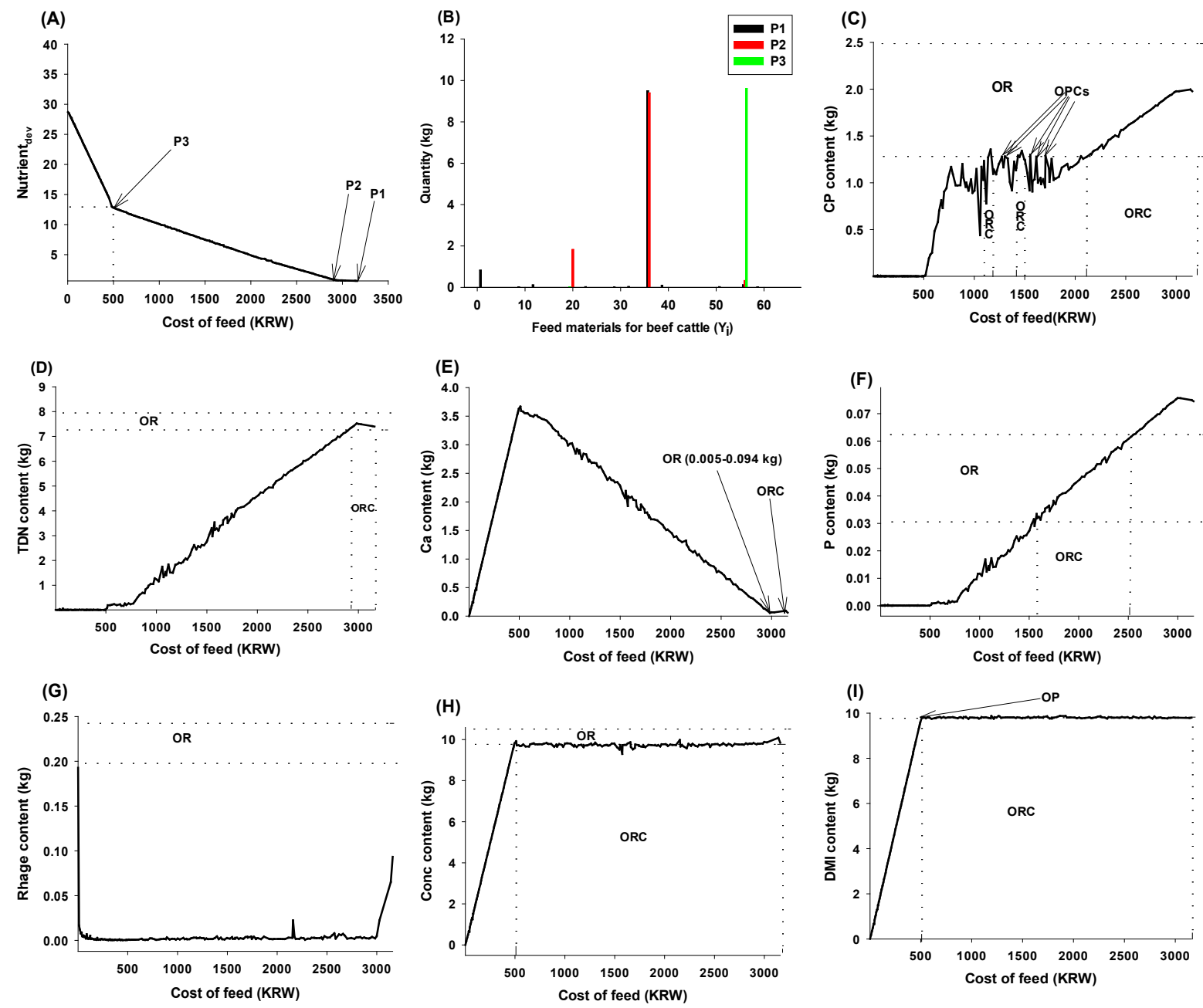

Figure 6. Feed formulation curves for beef cattle Case 2 (OR: Optimal Region; P1, P2, P3: Points; ORC: Optimal Region Cost; OP: Optimal Point; OPC: Optimal Point Cost; Nutrient $t_{\text {dev }}$ : Deviation in specified nutrients requirement)

\subsubsection{Beef: Case 3}

In Case 3 of beef cattle feed formulation, four distinct points were selected and analyzed (Figure 8A). P1 reasonably satisfied all the specified nutrient with exception of Rhage. However, moving leftward from P1 to P2, the Conc. deviated by $18 \%$ but cost reduced by $33 \%$. As in Case 1, Level 2, a similar trend was recorded at P3 
(Figure $8 \mathrm{H}$ ) and Rhage (Figure 8G) that was not met at all the points because of the reason explained in the Case
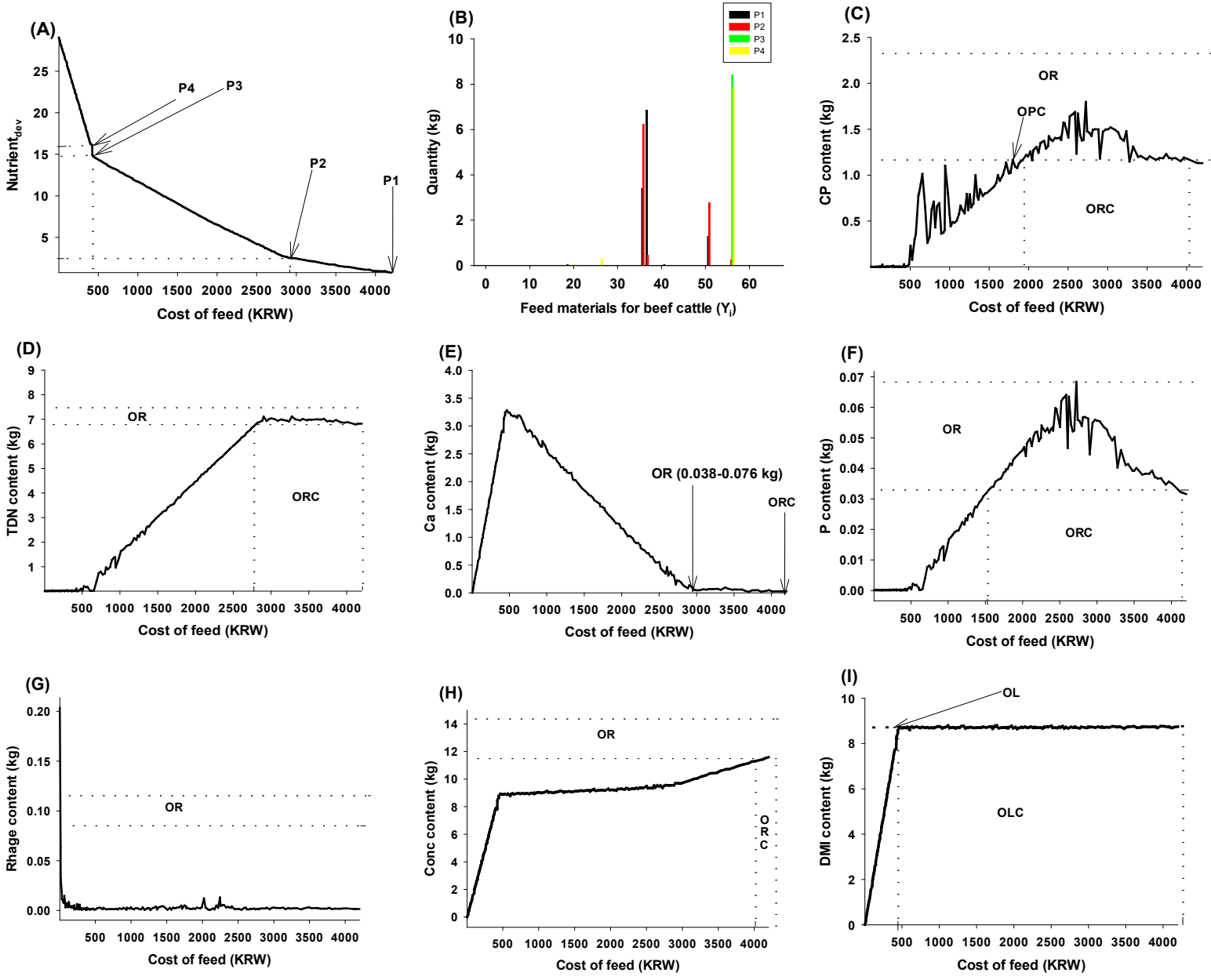

Figure 7. Feed formulation curves for beef cattle Case 3 (OR: Optimal Region; P1, P2, P3, P4: Points; ORC: Optimal Region Cost; OP: Optimal Point; OPC: Optimal Point Cost; Nutrient dev: Deviation in specified nutrients requirement)

\subsubsection{Beef: Case 4}

The final case analyzed in this study for beef cattle feed formulation mimicked the Pareto front in Case 3. P1 satisfied all the recommended nutrient requirement with exception of Rhage. As in Case 2, the P2 (Figure 9A) had satisfactory solutions except in Conc. content. (Figure 9H) which fell short by $21 \%$. All the points failed to meet the specified value for Rhage (Figure 9G). As in Case 3, P3 and P4 had different solutions with slight difference in cost although both points only met the recommended DMI (Figure 9I). Corn gluten meal, cottonseed, molasses and salt were the major materials selected at P1, soybean and wheat hull for P2 while $5.41 \mathrm{~kg}, 5.53 \mathrm{~kg}$ and $1.23 \mathrm{~kg}$ 

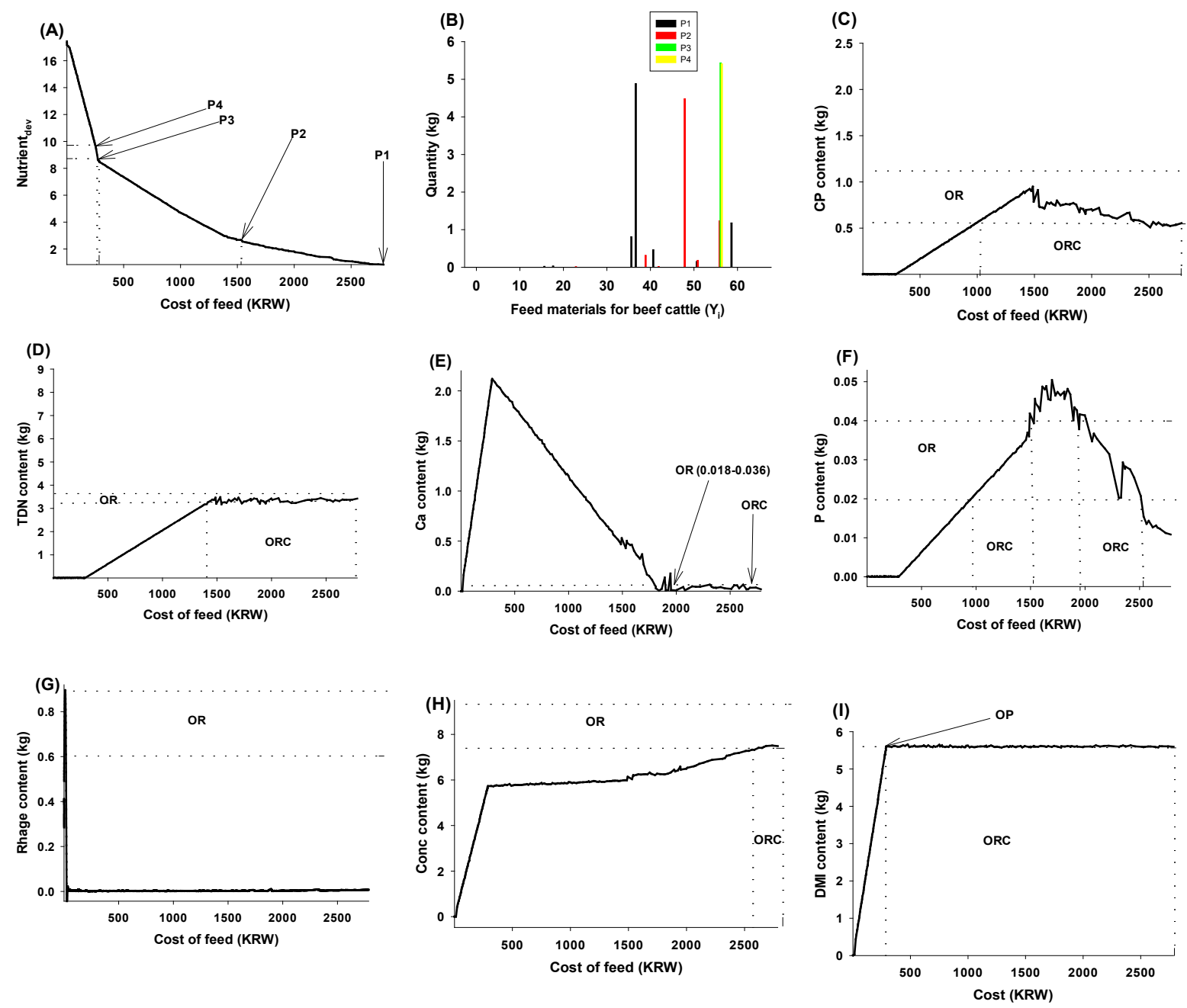

Figure 8. Feed formulation curves for beef cattle Case 4(OR: Optimal Region; P1, P2, P3, P4: Points; ORC: Optimal Region Cost; OP: Optimal Point; Nutrient dev : Deviation in specified nutrients requirement)

\section{Conclusion}

In this study, the conventional feed formulation approach which is a single objective constrained problem was formulated as a multi-objective problem. The multi-objective formulation was based on observations from previous studies that - a) relaxing some of the nutritional requirements does not affect the growth or performance of the animal and b) nutritional requirement satisfaction and feed cost were sometimes conflicting. Therefore, in the proposed multi-objective feed formulation, the feed cost and the deviation of the nutrients from the specified requirements were considered as two objectives. In addition, the use of evolutionary multi-objective optimization (NSGA-II) provided the set of entire comprise solutions in a single run. The availability of the entire Pareto front helped the feed formulator to make better decisions as it provided the relationships between different nutrients 


\section{Conflict of interest}

415 The authors declare that there is no conflict of interest.

\section{Acknowledgements}

418 This work was carried out with the support of "Cooperative Research Program for Agriculture Science \&

419 Technology Development (Project No.: PJ013871-02) Rural Development Administration, Republic of $420 \quad$ Korea

\section{$421 \quad$ References}

422 1. Tirana Noor Fatyanosa, Wayan Firdaus Mahmudy, and Marjuki Marjuki, A comparison of four types of evolution strategies for beef cattle feed optimization. Journal of Telecommunication, Electronic and Computer Engineering (JTEC), 2018. 10(1-8): p. 165-171.

2. National Research Council, Nutrient requirements of dairy cattle: 2001. 2001: National Academies Press.

3. National Research Council, Guide for the care and use of laboratory animals. 2010: National Academies

4. Elisa Sierra Montoya, Julian David Chará, and Rolando Barahona-Rosales, The nutritional balance of early lactation dairy cows grazing in intensive silvopastoral systems. Ciência Animal Brasileira, 2017. 18. Press. http://www.nias.go.kr/front/researchUtilizeBoardView.do?cmCode=M090918001117679\&cntntsNo=8 $507 \&$ columnName $=$ title \&searchStr $=$.

6. Zoran Babić and Tunjo Perić, Optimization of livestock feed blend by use of goal programming. International journal of production economics, 2011. 130(2): p. 218-223.

7. P Harris and REM Bishop, Recent developments in equine nutrition and feeding. Journal oft he Royal Agricultural Society of England, 2007. 168.

8. C. van de Panne and W. Popp, Minimum-cost cattle feed under probabilistic protein constraints. Management Science, 1963. 9(3): p. 405-430.

9. P Jean dit Bailleul, J Rivest, F Dubeau, and C Pomar, Reducing nitrogen excretion in pigs by modifying the traditional least-cost formulation algorithm. Livestock Production Science, 2001. 72(3): p. 199-211.

10. Timothy L Shaftel and Beverley M Wilson, A mixed-integer linear programming decision model for aquaculture. Managerial and Decision Economics, 1990. 11(1): p. 31-38.

11. Frederick V Waugh, The minimum-cost dairy feed (an application of" linear programming"). Journal of Farm Economics, 1951. 33(3): p. 299-310. 
12. Alan G Munford, The use of iterative linear programming in practical applications of animal diet formulation. Mathematics and computers in Simulation, 1996. 42(2-3): p. 255-261.

13. Carmen Castrodeza, Pablo Lara, and Teresa Peña, Multicriteria fractional model for feed formulation: Economic, nutritional and environmental criteria. Agricultural systems, 2005. 86(1): p. 76-96.

14. Victor E Smith, Linear programming models for the determination of palatable human diets. Journal of Farm Economics, 1959. 41(2): p. 272-283.

15. Joseph L Balintfy, A mathematical programming system for food management applications. Interfaces, 1975. 6(1-part-2): p. 13-31.

455

16. Ronald D Armstrong and Prabhakant Sinha, Application of quasi-integer programming to the solution of menu planning problems with variable portion size. Management Science, 1974. 21(4): p. 474-482.

17. Joseph L Balintfy, On a basic class of multi-item inventory problems. Management science, 1964. 10(2): p. 287-297.

18. David Sklan and Ilana Dariel, Diet planning for humans using mixed-integer linear programming. British Journal of Nutrition, 1993. 70(1): p. 27-35.

19. Tahir Rehman and Carlos Romero, Multiple-criteria decision-making techniques and their role in livestock ration formulation. Agricultural Systems, 1984. 15(1): p. 23-49.

20. Mehrdad Tamiz, Dylan Jones, and Carlos Romero, Goal programming for decision making: An overview of the current state-of-the-art. European Journal of operational research, 1998. 111(3): p. 569-581.

21. Dennis Minson, Forage in ruminant nutrition. 2012: Elsevier.

22. Eric John Underwood, The mineral nutrition of livestock. 1999: Cabi.

23. Uyeh Daniel Dooyum, Rammohan Mallipeddi, Trinadh Pamulapati, Tusan Park, Junhee Kim, Seungmin

24. Peter Zander and Harald Kächele, Modelling multiple objectives of land use for sustainable development.

25. Pablo Lara, Multiple objective fractional programming and livestock ration formulation: A case study for dairy cow diets in spain. Agricultural Systems, 1993. 41(3): p. 321-334.

27. F Zhang and WB Roush, Multiple-objective (goal) programming model for feed formulation: An example

28. J Prišenk, K Pažek, Č Rozman, J Turk, M Janžekovič, and A Borec, Application of weighted goal

29. Mary McCann-Rugg, Gregory P White, and Jeanette M Endres, Using goal programming to improve the

30. T. Pamulapati, R. Mallipeddi, and P. N. Suganthan, Isde+ - an indicator for multi and many-objective optimization. IEEE Transactions on Evolutionary Computation, 2018: p. 1-1. data. 2017 ; Available from: http://www.nias.go.kr/front/researchUtilizeBoardView.do?cmCode=M090918001117679\&cntntsNo=8 
32. Daniel Dooyum Uyeh, Rammohan Mallipeddi, Trinadh Pamulapati, Tusan Park, Junhee Kim, Seungmin Woo, and Yushin Ha, Interactive livestock feed ration optimization using evolutionary algorithms. Computers and Electronics in Agriculture, 2018. 155: p. 1-11.

33. Kalyanmoy Deb, Amrit Pratap, Sameer Agarwal, and TAMT Meyarivan, A fast and elitist multiobjective genetic algorithm: Nsga-ii. IEEE transactions on evolutionary computation, 2002. 6(2): p. 182-197.

34. C Wang, JX Liu, ZP Yuan, YM Wu, SW Zhai, and HW Ye, Effect of level of metabolizable protein on milk production and nitrogen utilization in lactating dairy cows. Journal of Dairy Science, 2007. 90(6): p. 2960-2965.

494

35. Pratiksha Saxena and Neha Khanna, Animal feed formulation: Mathematical programming techniques. CAB Reviews: Perspectives in Agriculture, Veterinary Science Nutrition and Natural Resources, 2014. 9(35): p. 1-12.

36. Leng R .A. Nutritional role of concentrate feeds and perspectives for their substitution based on recent advances in nutritional science. [cited 2019 22/1/2019]; Available from: http://www.fao.org/3/X6930E/X6930E04.htm. Nelgen, Integrating livestock feeds and production systems into agricultural multi-market models: The example of impact. Food Policy, 2014. 49: p. 365-377. 
505 Table A1. Feed materials and their nutritional values for dairy cattle in Republic of Korea

\begin{tabular}{|c|c|c|c|c|c|c|c|c|c|c|c|c|c|c|}
\hline ariables & $\begin{array}{l}\text { Cost } \\
(\mathrm{KRW} / \mathrm{kg}\end{array}$ & $\begin{array}{l}\text { Met } \\
(\mathrm{kg})\end{array}$ & $\begin{array}{l}\text { Lys } \\
\text { (kg) }\end{array}$ & $\begin{array}{l}\text { Arg } \\
(\mathbf{k g})\end{array}$ & $\begin{array}{l}\text { Thr } \\
\text { (kg) }\end{array}$ & $\begin{array}{l}\text { Leu } \\
\text { (kg) }\end{array}$ & $\begin{array}{l}\text { Ile } \\
\text { (kg) }\end{array}$ & $\begin{array}{l}\text { Val } \\
\text { (kg) }\end{array}$ & $\begin{array}{l}\begin{array}{l}\text { His } \\
(\mathrm{kg})\end{array}\end{array}$ & $\begin{array}{l}\text { Phe } \\
\text { (kg) }\end{array}$ & $\begin{array}{l}\text { Trp } \\
\text { (kg) }\end{array}$ & $\begin{array}{l}\text { ME } \\
\text { (Mcal/kg }\end{array}$ & $\begin{array}{l}\mathrm{Ca} \\
(\mathrm{kg})\end{array}$ & $\begin{array}{l}P \\
(\mathrm{~kg})\end{array}$ \\
\hline $\mathbf{X}_{1}$ Almond pie & 300 & 0.004 & 70.04 & 40.04 & 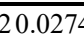 & +0.04 & 60.02 & & & & 70.0 & .0000 & 0.002 & 20.00 \\
\hline $\mathbf{X}_{2}$ Apple pie & 150 & 0.006 & 70.02 & 30.02 & & 30.0 & 90.0 & 30.0 & 30.0 & 00.0 & 00.0450 & 02.4900 & 0.002 & 30.0011 \\
\hline $\mathbf{X}_{3}$ Bakery by-p & 350 & 0.017 & $70.031^{\prime}$ & 70.0477 & 70.04 & 50.074 & 70.045 & 70.043 & 00.013 & 00.041 & 00.0100 & 03.2200 & 0.001 & 50.0024 \\
\hline $\mathbf{X}_{4}$ Beet pulp & 400 & 0.006 & 50.03 & 00.04 & & 70.0 & 10.0 & & & 70.028 & 300.0 & 02.6800 & 0.006 & 80.0010 \\
\hline $\mathbf{X}_{5}$ Citrus peel & 50 & 0.00 & 50.0 & 00.0 & & 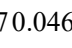 & 10.0 & 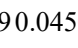 & & & 300.0 & .0000 & 0.014 & 30.0011 \\
\hline $\mathbf{X}_{6}$ Cotton seed & 400 & 0.0 & 10.0 & 50.11 & 00.0 & 40.0 & 70.0 & 40.0 & 90.0 & 0.000 & 90.0030 & 00.0000 & 0.001 & 50.0009 \\
\hline $\mathbf{X}_{7}$ Rice bran & 500 & 0.018 & 80.04 & 10.0701 & 10.0350 & 00.066 & 40.032 & 80.049 & 60.025 & 50.043 & 80.0088 & 82.5300 & 0.000 & 80.0173 \\
\hline $\mathbf{X}_{8}$ Tofu & 400 & 0.004 & 70.04 & 40.0472 & 20.02 & 40.048 & 60.024 & 60.033 & 00.01 & 40.029 & 90.0053 & 32.8900 & 0.005 & 30.0018 \\
\hline $\mathbf{X}_{9}$ Distillers dried grain (soju) & 380 & 0.007 & 50.0 & $70.0^{7}$ & 60.0 & 10.0 & 60.0 & 80. & 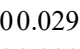 & 5 & 30. & 00.0000 & 0.001 & 30.0138 \\
\hline $\mathbf{X}_{10}$ Ca salt & 2000 & 0.0 & 00.0 & 00.0 & & 0.0 & 00.0 & 00.0 & & & 00.0 & 00.0000 & 0.120 & 00.0000 \\
\hline $\mathbf{X}_{11}$ Raw soy & 1200 & 0.011 & 10.0 & 70.0642 & 20.0 & 60.07 & 50.0 & 10.04 & 10.0 & 60.048 & 10.0164 & 43.2200 & 0.002 & 70.0065 \\
\hline $\mathbf{X}_{12} \mathrm{Ba}$ & 390 & 0.008 & 10.0 & 70.0483 & 30.0 & 50.0 & 30.039 & 20.04 & 80.02 & 90.056 & 500.0126 & 63.0400 & 0.000 & 50.0035 \\
\hline $\mathbf{X}_{13}$ Corn & 400 & 0.011 & 20.0 & 50.0 & 20.0 & 00.1 & 00.0 & 90.0 & 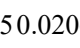 & 6 & 550. & 73.1800 & 0.000 & 30.0032 \\
\hline $\mathbf{X}_{14}$ Shred & 450 & 0.01 & م0مد & 50.0 & 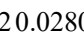 & 0.1 & 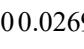 & 90.0 & .0 & .0 & 0.0 & 600 & 0.000 & 30.0031 \\
\hline $\mathbf{X}_{15}$ Mola & 150 & 0.000 & 00.0 & 00.0 & 00.0 & 00.0 & 00.0 & 00.0 & 00.0 & 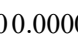 & 00.0 & 02.1700 & 0.010 & 00.0010 \\
\hline $\mathbf{X}_{16}$ Oat & 500 & 0.021 & 20.02 & 20.0438 & 80.0 & 60.0 & 00.038 & $40.0 \mathrm{c}$ & 00.0 & 00.058 & 360.0128 & 82.6400 & 0.000 & 70.0030 \\
\hline $\mathbf{X}_{17}$ Rice & 60 & 0.02 & 00.0 & 00.0 & 00.0 & 00.0 & 00.0 & 00.0 & 00 & 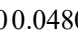 & 300.0 & 02.8600 & 0.000 & 70.0036 \\
\hline $\mathbf{X}_{18}$ Rye & 35 & 0.01 & 80.0 & 70.0 & 20. & 70.0 & 00.0 & 40. & 0.0 & $0.0^{2}$ & 540. & 3.0400 & 0.000 & 70.0036 \\
\hline $\mathbf{X}_{19}$ Sorgl & 3 & 0.0 & 7 & 70.0 & & 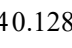 & 00.0 & & & & & 500 & 0. & 50 \\
\hline $\mathbf{X}_{\mathbf{2 0}}$ Tallow & 11 & 0.000 & 00.0 & 00.0000 & 00.0 & 00.0 & 00.000 & 00.0 & 00.0 & 0.0 & 00.0 & 03.6200 & 0.005 & 70.0006 \\
\hline $\mathbf{X}_{21}$ Wheat & 390 & 0.009 & 80.0 & 00.043 & 30.0 & 20.1 & 00.039 & 80.0 & 00.0 & 00 & 340.0 & 63.0700 & 0.000 & 70.0033 \\
\hline $\mathbf{X}_{22}$ Barley & 40 & 0.01 & 30.0 & 50.0 & 30.0 & 40.0 & 50.0 & 50.0 & 0 & 9 & 40.0 & 52.3500 & 0.005 & 20.0029 \\
\hline $\mathbf{X}_{23}$ Cor & 250 & 0.00 & 60.01 & 40.0 & 00.0 & 20.1 & 00.0 & 20.0 & 0. & 0.0 & 00 & 81.8100 & 0.001 & 20.0004 \\
\hline $\mathbf{X}_{24}$ Cor & 130 & 0.008 & 00.02 & 30.0 & 70. & 30.0 & 00.0 & 00.0 & 00.0 & 9. & 40. & 00 & 0.002 & 30.0021 \\
\hline $\begin{array}{l}\mathbf{X}_{25} \text { Corn } \\
\text { stage }\end{array}$ & 120 & 0.00 & 00.02 & 30.0187 & 70.0 & 30.0 & 00.0 & 00.0 & 00.0 & 70.0 & 40.0 & 12.3900 & 0.003 & 10.0027 \\
\hline${ }_{26} \mathrm{Co}$ & & & & & & & & & & & & & & \\
\hline${ }_{27}^{2}$ Hay & 4 & 0.006 & 70. & 30 & & 30. & 90.0 & & 0. & & & 0 & 0. & \\
\hline $\mathbf{X}_{28}$ Oat s & 10 & .0 & 70.0 & 30.0 & 30. & 30. & 90.0 & 30.0 & 30.0 & 5 & 000. & 2.0600 & 0.005 & 80.0031 \\
\hline $\mathbf{X}_{29} \mathrm{Och}$ & 30 & 0.006 & 70.02 & 30.02 & 30.0 & 30.0 & 90.02 & 30.0 & 30.01 & .035 & 00.0 & 01.6300 & 0.002 & 30.0006 \\
\hline $\mathbf{x}_{\mathbf{3 0}} \mathrm{Wh}$ & 25 & 0.006 & 70.02 & 30.02 & 30.0 & 30. & 90.028 & 30.0 & 30.0 & 0.035 & 00. & 01.5900 & 0.001 & 70.0005 \\
\hline $\mathbf{X}_{31} \mathrm{Ba}$ & 250 & 0.00 & 70.0 & 30.0 & 30. & 30.0 & 90.0 & 30.0 & 0.8 & 0.0 & 00. & 01.4500 & 0.003 & 00.0007 \\
\hline $\mathbf{X}_{32}$ Tor & 400 & 0.0 & 70 & 30.0 & 30. & $0 .($ & 90.0 & & 0.0 & 5 & 00 & 2.1000 & 0.004 & 30.0032 \\
\hline $\mathbf{X}_{33}$ Herb & 16 & 0.00 & 7 & 30.0 & 30. & 30. & 90.0 & 30. & 0.0 & 0.0 & 00 & 0.0000 & 0.003 & 10.0014 \\
\hline $\mathbf{X}_{34} \mathrm{Mi}$ & 10 & 0.007 & 00.0 & 30.0 & 10.0 & 20.0 & 80.0 & 20.0 & .0 & 0.0 & 10.0 & 50.0000 & 0.013 & 00.0036 \\
\hline $\mathbf{X}_{35}$ Or & 42 & 0.006 & 70.02 & 30.0283 & 30.0 & 30.0 & 90.028 & 30.0 & 30.0 & 0.035 & 00.0 & 01.9500 & 0.002 & 60.0030 \\
\hline $\mathbf{X}_{36}$ Forage (au & 55 & 0.0 & 700 & 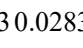 & & 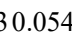 & 90.0 & & 001 & & 500. & 01.9200 & 0.005 & 50.0045 \\
\hline $\mathbf{X}_{37}$ Forage (spring) & 60 & 0.006 & 70 & 30.0 & 30.0 & 0.0 & 90.0 & 30.0 & 0.0 & 5 & 00 & 02.6800 & 0.002 & 70.0034 \\
\hline $\mathbf{X}_{38}$ Forage (s & 50 & 0.006 & 70.02 & 30.02 & 30.02 & 30.0 & 90.028 & 30.0 & 30.01 & 0.035 & 00.0450 & 02.4200 & 0.002 & 90.0028 \\
\hline $\mathbf{X}_{39} \operatorname{Mix}$ & 60 & 0.007 & 00.0 & 30.0 & 10.0 & 20.0 & 80.044 & 20.0 & 90.0 & 0.049 & 10.0 & 20.0000 & 0.000 & 00.0000 \\
\hline${ }_{40} \mathrm{Mi}$ & 5 & 0.00 & 000 & 30.0 & 10 & 20.0 & 80.0 & 20.0 & & & & 0 & 0.000 & 00.0000 \\
\hline $\mathbf{X}_{41}$ Rye grass hay & 35 & 0. & 70 & 30. & 30 & 30. & 90.0 & 30. & & & 00 & 2.3100 & 0.006 & 50.0032 \\
\hline $\mathbf{X}_{42}$ Sudan grass ha & 350 & 0.006 & 70.02 & 30.028 & 30.0 & 30.0 & 90.028 & 30.0 & 30.01 & 00.035 & 00.0450 & 02.0300 & 0.005 & 10.0031 \\
\hline $\mathbf{X}_{43}$ Timothy hay & 500 & 0.006 & 70.02 & 30.0283 & 30.02 & 30.05 & 90.028 & 30.03 & 30.010 & 00.035 & 00.0450 & 02.1300 & 0.005 & 10.0029 \\
\hline $\mathbf{X}_{44}$ Alfalfa hay & 520 & 0.007 & 30.0 & 20.063 & 90.0 & 00.0 & 60.060 & 10.07 & 140 & Pि & 20.0184 & 41.8800 & 0.011 & 90.0024 \\
\hline $\mathbf{X}_{45}$ Alfalfa silage & 200 & 0.007 & م & & 90.0 & 00.0 & 60.0 & 10.0 & 08 & 0.0 & 20.0 & 40.0000 & 0.017 & 40.0027 \\
\hline $\mathbf{X}_{46}$ Alfalfa pellet & 359 & 0.007 & 30.0 & 20.0639 & 90.0 & 00.0 & 60.06 & 10.0 & 0.02 & 20.0 & 20.0 & 42.1300 & 0.013 & 80.0025 \\
\hline $\mathbf{X}_{47}$ Di-Ca phos & 700 & 0.000 & 00.0 & 00.0000 & 00.0 & 00.00 & 00.00 & 00.0 & 00.0 & 0.000 & 00.0000 & 00.0000 & 0.220 & 00.1930 \\
\hline $\mathbf{X}_{48} \mathrm{Lir}$ & 30 & 0.0 & 00.0 & 00.0 & 00.0 & 00.0 & 00.0 & 00.0 & 0 & 0.0 & 00.0 & 00.0000 & 0.340 & 00.0002 \\
\hline $\mathbf{X}_{49}$ Oyster shell & 100 & & & 00.0 & & 00.0 & 00.0 & & & 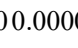 & & 00.0000 & 0.380 & 00.0007 \\
\hline $\mathbf{X}_{50}$ Ca phosphate & 500 & & & & & 00.0 & 00.0 & & & 0.0 & 00.0 & 00.0000 & 0.320 & 00.1800 \\
\hline $\mathbf{X}_{51}$ Potassium chloride & 560 & 0.000 & 00.000 & 00.0000 & 00.00 & 00.000 & 00.000 & 00.00 & 00.00 & 0.00 & 00.0000 & 00.0000 & 0.001 & 50.0000 \\
\hline $\mathbf{X}_{52}$ Distillers grain & 60 & 0.017 & 00.03 & 30.0465 & 90.03 & 30.091 & 80.057 & 10.05 & 50.01 & 00.05 & 10.0136 & 62.5300 & 0.002 & 90.0070 \\
\hline $\mathbf{X}_{53}$ Dried distillers' & 400 & 0.012 & 60.021 & 50.0261 & 10.027 & 60.084 & 60.035 & 30.037 & 80.014 & 70.048 & 300.0112 & 22.4200 & 0.002 & 90.0070 \\
\hline
\end{tabular}




\begin{tabular}{llll}
$\mathbf{X}_{54}$ Corn gluten feed & 300 & 0.02090 .01240 .03170 .02930 .16200 .04340 .05040 .02450 .06480 .00373 .0000 & 0.00070 .0095 \\
$\mathbf{X}_{55}$ Corn gluten meal & 700 & 0.02090 .01240 .03170 .02930 .16200 .04340 .05040 .02450 .06480 .00373 .2200 & 0.00070 .0061 \\
$\mathbf{X}_{56}$ Whole soybean & 900 & 0.00630 .03850 .10400 .03450 .06330 .03770 .05270 .03140 .05850 .01743 .4400 & 0.00160 .0062 \\
$\mathbf{X}_{57}$ Cotton seed meal & 350 & 0.00990 .04500 .10600 .03390 .06310 .03620 .05020 .03450 .05470 .01742 .7100 & 0.00200 .0116 \\
$\mathbf{X}_{58}$ Dried distillers' grain & 400 & 0.01200 .02060 .04150 .03120 .09070 .02780 .05240 .01820 .04200 .01643 .1100 & 0.00260 .0083 \\
$\mathbf{X}_{59}$ Wet distillers' grain & 150 & 0.01200 .02060 .04150 .03120 .09070 .02780 .05240 .01820 .04200 .01643 .2500 & 0.00320 .0140 \\
$\mathbf{X}_{60}$ Linseed meal & 380 & 0.01950 .04310 .10700 .04220 .06800 .05370 .05760 .02520 .05250 .01633 .2200 & 0.00430 .0089 \\
$\mathbf{X}_{61}$ Lupine & 480 & 0.01010 .07060 .09370 .03530 .06930 .04080 .04620 .02480 .04620 .00762 .8200 & 0.00260 .0044 \\
$\mathbf{X}_{62}$ Peanut meal & 360 & 0.01100 .03140 .10900 .02530 .06060 .03160 .03820 .02180 .04920 .00983 .0000 & 0.00320 .0066 \\
$\mathbf{X}_{63}$ Soybean meal & 500 & 0.01010 .05360 .06550 .03520 .07230 .04650 .05090 .02820 .04940 .01643 .0400 & 0.00400 .0071 \\
$\mathbf{X}_{64}$ Molten soybean meal & 550 & 0.00830 .06080 .07690 .03030 .06130 .04250 .03790 .02270 .03880 .01643 .1500 & 0.00290 .0071 \\
\hline
\end{tabular}

507 Table A2. Feed materials and their nutritional values for beef cattle in Republic of Korea

\begin{tabular}{|c|c|c|c|c|c|c|c|c|}
\hline Variables & & $\begin{array}{l}\text { Cost } \\
(\mathrm{KRW} / \mathrm{kg})\end{array}$ & $\begin{array}{l}\mathrm{DM} \\
(\%) \\
\end{array}$ & $\begin{array}{l}\mathrm{MC} \\
(\%) \\
\end{array}$ & $\begin{array}{l}\text { TDN } \\
(\mathrm{kg})\end{array}$ & $\begin{array}{l}\text { C.P. } \\
(\mathrm{kg}) \\
\end{array}$ & $\begin{array}{l}\mathrm{Ca} \\
(\mathrm{kg}) \\
\end{array}$ & $\begin{array}{l}\mathrm{P} \\
(\mathrm{kg}) \\
\end{array}$ \\
\hline \multicolumn{9}{|c|}{ Roughages } \\
\hline $\mathrm{Y}_{1}$ & Rice straw (moisture $40 \%$ ) & 200 & 60.0000 & 40.0000 & 0.2940 & 0.0249 & 0.0023 & 0.0012 \\
\hline $\mathrm{Y}_{2}$ & Rye straw & 150 & 91.2000 & 8.8000 & 0.4780 & 0.0406 & 0.0030 & 0.0002 \\
\hline $\mathrm{Y}_{3}$ & Perennial rye grass hay & 400 & 89.9000 & 10.1000 & 0.5600 & 0.1250 & 0.0020 & 0.0028 \\
\hline $\mathrm{Y}_{4}$ & Perennial rye grass straw & 350 & 91.8000 & 8.2300 & 0.4190 & 0.0454 & 0.0028 & 0.0013 \\
\hline $\mathrm{Y}_{5}$ & Barley & 150 & 87.6000 & 12.4000 & 0.4110 & 0.0510 & 0.0035 & 0.0010 \\
\hline $\mathrm{Y}_{6}$ & Barley whole crop silage & 150 & 36.7000 & 63.3000 & 0.2240 & 0.0338 & 0.0027 & 0.0007 \\
\hline $\mathrm{Y}_{7}$ & Sudan grass & 170 & 29.1000 & 70.9000 & 0.1750 & 0.0185 & 0.0024 & 0.0016 \\
\hline $\mathrm{Y}_{8}$ & Alfalfa hay & 600 & 90.7000 & 9.3400 & 0.5260 & 0.1600 & 0.0126 & 0.0027 \\
\hline $\mathrm{Y}_{9}$ & Oats hay & 400 & 88.1000 & 11.9000 & 0.5020 & 0.0461 & 0.0023 & 0.0021 \\
\hline $\mathrm{Y}_{10}$ & Oats silage & 200 & 29.6000 & 70.4000 & 0.1600 & 0.0240 & 0.0052 & 0.0031 \\
\hline $\mathrm{Y}_{11}$ & Corn silage & 500 & 89.6000 & 10.4000 & 0.5110 & 0.0790 & 0.0012 & 0.0013 \\
\hline $\mathrm{Y}_{12}$ & Corn stalk & 200 & 89.4000 & 10.7000 & 0.2750 & 0.0477 & 0.0040 & 0.0011 \\
\hline $\mathrm{Y}_{13}$ & Corn silage (yellow ripe stage) & 200 & 22.5000 & 77.5000 & 0.1440 & 0.0262 & 0.0002 & 0.0006 \\
\hline $\mathrm{Y}_{14}$ & Rape stalk & 150 & 85.6000 & 14.4000 & 0.3610 & 0.0483 & 0.0108 & 0.0012 \\
\hline $\mathrm{Y}_{15}$ & Italian ryegrass hay & 450 & 90.1000 & 9.8900 & 0.5500 & 0.0856 & 0.0048 & 0.0030 \\
\hline $\mathrm{Y}_{16}$ & Italian ryegrass silage $(40 \%)$ & 150 & 60.0000 & 40.0000 & 0.3660 & 0.1400 & 0.0106 & 0.0062 \\
\hline $\mathrm{Y}_{17}$ & Italian ryegrass silage $(67 \%)$ & 140 & 32.9000 & 67.1000 & 0.2010 & 0.0769 & 0.0058 & 0.0034 \\
\hline \multicolumn{9}{|c|}{ By-products } \\
\hline $\mathrm{Y}_{18}$ & Citrus peel & 70 & 13.0000 & 87.0000 & 0.1080 & 0.0112 & 0.0002 & 0.0002 \\
\hline $\mathrm{Y}_{19}$ & Radish by-product & 30 & 6.0100 & 94.0000 & 0.0474 & 0.0035 & 0.0026 & 0.0001 \\
\hline $\mathrm{Y}_{20}$ & Corn meal & 30 & 37.9000 & 62.1000 & 0.2280 & 0.0176 & 0.0001 & 0.0010 \\
\hline $\mathrm{Y}_{21}$ & Brewers grain & 70 & 26.2000 & 73.8000 & 0.1860 & 0.0555 & 0.0006 & 0.0010 \\
\hline $\mathrm{Y}_{22}$ & Mushroom by-product(oyster) & 100 & 37.5000 & 62.5000 & 0.1730 & 0.0409 & 0.0081 & 0.0016 \\
\hline $\mathrm{Y}_{23}$ & Mushroom by-product (King Oyster) & 90 & 40.2000 & 59.8000 & 0.1850 & 0.0532 & 0.0070 & 0.0007 \\
\hline $\mathrm{Y}_{24}$ & Mushroom by-product(winter) & 70 & 44.2000 & 55.8000 & 0.2210 & 0.0414 & 0.0120 & 0.0034 \\
\hline $\mathrm{Y}_{25}$ & Malt meal & 250 & 62.4000 & 37.6000 & 0.5050 & 0.2170 & 0.0015 & 0.0018 \\
\hline $\mathrm{Y}_{26}$ & Ground bean (moisture 60\%) & 90 & 40.0000 & 60.0000 & 0.3240 & 0.0945 & 0.0034 & 0.0016 \\
\hline $\mathrm{Y}_{27}$ & Ground bean (moisture 80\%) & 70 & 19.7000 & 80.3000 & 0.1600 & 0.0466 & 0.0017 & 0.0008 \\
\hline $\mathrm{Y}_{28}$ & Apple pomace & 100 & 20.9000 & 79.2000 & 0.1590 & 0.0083 & 0.0008 & 0.0001 \\
\hline $\mathrm{Y}_{29}$ & Rice bran & 250 & 88.3000 & 11.8000 & 0.7680 & 0.1310 & 0.0008 & 0.0186 \\
\hline $\mathrm{Y}_{30}$ & Bakery by-product & 250 & 90.0000 & 10.0000 & 0.8650 & 0.1270 & 0.0003 & 0.0013 \\
\hline $\mathrm{Y}_{31}$ & Distillers dried grains (Soju) & 70 & 25.0000 & 75.0000 & 0.1260 & 0.0866 & 0.0001 & 0.0001 \\
\hline $\mathrm{Y}_{32}$ & Distillers dried grains (Takju) & 50 & 17.5000 & 82.5000 & 0.1270 & 0.0666 & 0.0002 & 0.0004 \\
\hline $\begin{array}{l}Y_{33} \\
\text { Conc }\end{array}$ & Pineapple peel & 110 & 59.6000 & 40.4000 & 0.3760 & 0.0346 & 0.0064 & 0.0015 \\
\hline $\mathrm{Y}_{34}$ & Hulled barley & 500 & 87.0000 & 13.0000 & 0.7200 & 0.1200 & 0.0018 & 0.0018 \\
\hline $\mathrm{Y}_{35}$ & Oat & 400 & 89.0000 & 11.0000 & 0.7000 & 0.0900 & 0.0011 & 0.0030 \\
\hline $\mathrm{Y}_{36}$ & Corn gluten feed & 300 & 92.3000 & 7.7200 & 0.7300 & 0.2000 & 0.0013 & 0.0076 \\
\hline $\mathrm{Y}_{37}$ & Molasses & 400 & 64.4000 & 35.6000 & 0.4800 & 0.0500 & 0.0036 & 0.0003 \\
\hline & & & & & & & & \\
\hline
\end{tabular}




\begin{tabular}{|c|c|c|c|c|c|c|c|c|}
\hline $\mathrm{Y}_{38}$ & Soybean meal & 600 & 88.1000 & 11.9000 & 0.7600 & 0.4600 & 0.0035 & 0.0064 \\
\hline $\mathrm{Y}_{39}$ & Soybean hull & 300 & 90.4000 & 9.5700 & 0.5700 & 0.0900 & 0.0053 & 0.0009 \\
\hline $\mathrm{Y}_{40}$ & Lupin seed & 600 & 90.0000 & 10.1000 & 0.8500 & 0.3000 & 0.0028 & 0.0036 \\
\hline$Y_{41}$ & Cottonseed & 500 & 88.9000 & 11.1000 & 0.7400 & 0.2800 & 0.0014 & 0.0055 \\
\hline $\mathrm{Y}_{42}$ & Cottonseed oil meal & 400 & 89.4000 & 10.6000 & 0.6100 & 0.3600 & 0.0021 & 0.0095 \\
\hline $\mathrm{Y}_{43}$ & Cottonseed hulls & 300 & 91.4000 & 8.6100 & 0.4000 & 0.0800 & 0.0044 & 0.0025 \\
\hline $\mathrm{Y}_{44}$ & Formula feed & 420 & 88.0000 & 12.0000 & 0.7200 & 0.1400 & 0.0060 & 0.0040 \\
\hline $\mathrm{Y}_{45}$ & Pearl barley & 500 & 87.5000 & 12.5000 & 0.7400 & 0.1100 & 0.0006 & 0.0033 \\
\hline $\mathrm{Y}_{46}$ & Beet pulp & 600 & 89.1000 & 10.9000 & 0.8500 & 0.0900 & 0.0036 & 0.0003 \\
\hline $\mathrm{Y}_{47}$ & Wheat & 500 & 88.3000 & 11.7000 & 0.7400 & 0.1100 & 0.0005 & 0.0031 \\
\hline $\mathrm{Y}_{48}$ & Wheat hulls & 300 & 87.8000 & 12.2000 & 0.6500 & 0.1500 & 0.0010 & 0.0095 \\
\hline $\mathrm{Y}_{49}$ & Sorghum & 500 & 83.8000 & 16.2000 & 0.7200 & 0.0900 & 0.0006 & 0.0040 \\
\hline $\mathrm{Y}_{50}$ & Rice & 500 & 86.2000 & 13.8000 & 0.7800 & 0.0700 & 0.0002 & 0.0009 \\
\hline $\mathrm{Y}_{51}$ & Corn & 312 & 87.3000 & 12.7000 & 0.7800 & 0.0700 & 0.0007 & 0.0026 \\
\hline \multicolumn{9}{|c|}{ Supplements } \\
\hline $\mathrm{Y}_{52}$ & Yeast & 1000 & 92.1000 & 7.9300 & 0.7720 & 0.4430 & 0.0013 & 0.0146 \\
\hline $\mathrm{Y}_{53}$ & Urea & 600 & 95.0000 & 5.0000 & 0.0000 & 2.8100 & 0.0000 & 0.0000 \\
\hline $\mathrm{Y}_{54}$ & Yeast culture & 1200 & 86.5000 & 13.5000 & 0.0000 & 0.1390 & 0.0003 & 0.0013 \\
\hline $\mathrm{Y}_{55}$ & Ca phosphate & 850 & 97.6000 & 2.4000 & 0.0000 & 0.0000 & 0.3100 & 0.1800 \\
\hline $\mathrm{Y}_{56}$ & Limestone & 50 & 97.6000 & 2.4000 & 0.0000 & 0.0000 & 0.3700 & 0.0000 \\
\hline $\mathrm{Y}_{57}$ & Vitamin mineral & 2000 & 95.0000 & 5.0000 & 0.0000 & 0.0000 & 0.0000 & 0.0000 \\
\hline $\mathrm{Y}_{58}$ & Sodium bicarbonate & 880 & 99.0000 & 1.0000 & 0.0000 & 0.0000 & 0.0000 & 0.0000 \\
\hline $\mathrm{Y}_{59}$ & Salt & 250 & 95.0000 & 5.0000 & 0.0000 & 0.0000 & 0.0000 & 0.0000 \\
\hline
\end{tabular}


510 Multi-objective Evolutionary Algorithms are population-based algorithms applied to solve two objectives

511 possessing conflicting characteristics. The main advantage of MOEAs are providing a set of solutions rather than

512 a single solution. Among all the MOEAs, NSGA-II is a more popular and widely adopted algorithm for real-world

513 applications. In NSGA-II, a randomly generated N population evaluates the objective function to provide a final

514 set of trade-off solutions using the operations like mutation, crossover and environmental selection. This process

515 is repeated until the termination criteria is met. The variation operators (polynomial mutation and binomial

516 crossover) are used to provide better offspring for the current populations and then selection is done using non-

517 dominated sorting followed by crowding distance. The ultimate goals of any MOEA is convergence and diversity.

518 In NSGA-II, the pareto dominance of final trade off solutions can be obtained by using procedures like non-

519 dominated sorting and crowding distance.

520 Basic definitions used in NSGA-II:

521 Offspring Generation: Generate same N population using some variation operators like mutation and crossover.

522 Mutation and crossover: Produce new solutions from the parent population by modifying some of its 523 characteristics.

524 Environmental Selection: Finding the best N possible solutions from the available $2 \mathrm{~N}$ solutions for the next

525 generation using some primary and secondary selection methods. In NSGA-II, the primary selection is done using 526 non-dominated Sorting of solutions on pareto fronts. Secondary selections are done using Crowding Distance 527 measure.

528 Non-dominated solution: A solution which dominates other solutions in at least one objective or in all objectives 529 is called a non-dominated solution.

530 Crowding Distance: This reflects the density of an individual, only acting on the two closest neighbors located 531 in either side for each objective or the cuboid distance of an individual with respect to the two nearest neighbors.

532 This is known as crowding distance of that solution. 


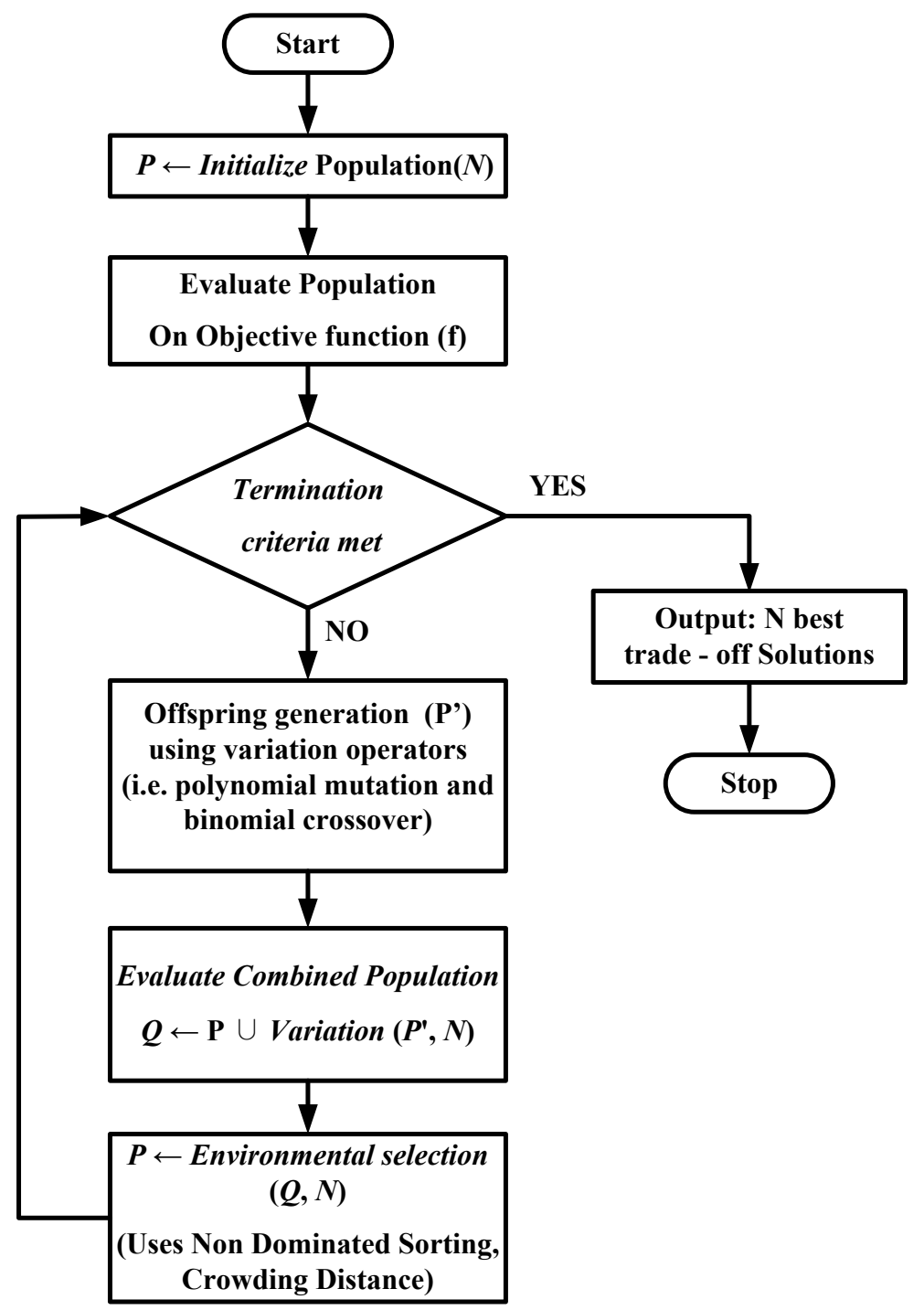

Figure A1. Flowchart of NSGA-II 